Quantum Electronic Structure

Subscriber access provided by King Abdullah University of Science and Technology Library

\title{
Application of Semiempirical Methods to Transition Metal Complexes: Fast Results but Hard-to-Predict Accuracy.
}

\author{
Yury Minenkov, Dmitry I. Sharapa, and Luigi Cavallo
}

J. Chem. Theory Comput., Just Accepted Manuscript • DOI: 10.1021/acs.jctc.8b00018 • Publication Date (Web): 22 May 2018

Downloaded from http://pubs.acs.org on May 29, 2018

\section{Just Accepted}

"Just Accepted" manuscripts have been peer-reviewed and accepted for publication. They are posted online prior to technical editing, formatting for publication and author proofing. The American Chemical Society provides "Just Accepted" as a service to the research community to expedite the dissemination of scientific material as soon as possible after acceptance. "Just Accepted" manuscripts appear in full in PDF format accompanied by an HTML abstract. "Just Accepted" manuscripts have been fully peer reviewed, but should not be considered the official version of record. They are citable by the Digital Object Identifier (DOI®). "Just Accepted" is an optional service offered to authors. Therefore, the "Just Accepted" Web site may not include all articles that will be published in the journal. After a manuscript is technically edited and formatted, it will be removed from the "Just Accepted" Web site and published as an ASAP article. Note that technical editing may introduce minor changes to the manuscript text and/or graphics which could affect content, and all legal disclaimers and ethical guidelines that apply to the journal pertain. ACS cannot be held responsible for errors or consequences arising from the use of information contained in these "Just Accepted" manuscripts. 


\title{
Application of Semiempirical Methods to Transition
}

\section{Metal Complexes: Fast Results but Hard-to-Predict}

\author{
Accuracy. \\ Yury Minenkov, *\$, † Dmitry I. Sharapał and Luigi Cavallo*广 \\ $\S$ Moscow Institute of Physics and Technology, Institutskiy Pereulok 9, Dolgoprudny, Moscow \\ Region 141700, Russia \\ $\dagger$ KAUST Catalysis Center (KCC), King Abdullah University of Science and Technology, \\ Thuwal-23955-6900, Saudi Arabia \\ $\ddagger$ Chair of Theoretical Chemistry and Interdisciplinary Center for Molecular Materials Friedrich- \\ Alexander-Universität Erlangen-Nürnberg Egerlandstraße3, 91058 Erlangen, Germany
}

KEYWORDS: Conformational Sampling, Density Functional Theory, Transition Metals, Conformational Energies, Semiempirical Methods.

\begin{abstract}
.
A series of semiempirical PM6* and PM7 methods has been tested in reproducing of relative conformational energies of 27 realistic-size complexes of 16 different transition metals (TMs).
\end{abstract}


An analysis of relative energies derived from single-point energy evaluations on density functional theory (DFT) optimized conformers revealed pronounced deviations between semiempirical and DFT methods, indicating fundamental difference in potential energy surfaces (PES). To identify the origin of the deviation, we compared fully optimized PM7 and respective DFT conformers. For many complexes, differences in PM7 and DFT conformational energies have been confirmed often manifesting themselves in false coordination of some atoms $(\mathrm{H}, \mathrm{O})$ to TMs and chemical transformations/distortion of coordination center geometry in PM7 structures. Despite geometry optimization with fixed coordination center geometry leads to some improvements in conformational energies, the resulting accuracy is still too low to recommend explored semiempirical methods for out-of-the-box conformational search/sampling: careful testing is always needed.

\section{Introduction}

Transition metal (TM) complexes bearing large bulky ligands are examples of important catalysts, both in vivo and in the chemical and pharmaceutical industry. ${ }^{1-5}$ To better understand their catalytic activity and physical properties, theoretical modelling of these complexes is today routinely undertaken and accounts for a significant fraction of the computational resources used worldwide. ${ }^{6-11}$ The complex electronic structure of TM (which is responsible for their catalytic activity), implies a number of computational challenges for an accurate modelling, such as relativistic effects, dynamic and static correlation effects, poor scalability of the reliable theoretical methods, and multiple low-lying electronic states. ${ }^{8,}{ }^{12-20}$ Numerous strategies have been proposed to overcome these issues, and many instructive results have been obtained. ${ }^{21-47}$ An 
additional important challenge, the strong conformational flexibility of many TM species, has so far received only limited attention from selected research groups, ${ }^{48-58}$ and is to large extent still an unsolved problem. This leads to known difficulties in the modeling of large TM complexes containing multiple rotatable bonds.

Accurate conformational search and/or sampling have been shown to be relevant for a number of cases related to molecular modelling. First, these are useful for modelling of chemical reactivity since a reaction may not arise from the most stable conformation, and conformational transitions are often required to initiate a chemical reaction. Moreover, as shown by Besora and co-workers, the errors originated from choosing wrong conformations can alter the calculated energy profiles by as much as $10-20 \mathrm{kcal} / \mathrm{mol} .{ }^{50,55}$ Second, reliable conformational sampling is often required for interpretation of physical experiments, like NMR, ${ }^{59}$ gas phase electron diffraction or dipole-moment experiments, ${ }^{60}$ in order to perform a proper Boltzmann averaging over the conformational space. Third, conformational sampling is sometimes needed for quantitative structure activity relationship (QSAR) studies aimed at identifying better catalysts or drug design because molecular descriptors can be sensitive to the conformations, and using only the most stable conformation might not be sufficient for reliable predictions. ${ }^{61}$

To solve these issues and make accurate calculations of conformational flexible systems possible, a fast and reliable approach to sample the conformational space of the molecule is of paramount importance. Needless to say, this is a daunting task since the complexity of this problem is exponential $\left(\mathrm{O}^{\mathrm{N}}\right)$. A systematic conformational search thus implies minimization of the energy function ca. $3^{N}$ times, where $N$ is the number of rotatable bonds. To get reliable relative energy estimates for TM complexes, the energy function from sophisticated wave or density function theory (DFT) should be used. These energy functions, however, are so 
computationally intensive that only systems with a few dozens of atoms and $3-4$ rotatable bonds can be subjected to an exhaustive conformational search. A possible way to solve these issues is to use computationally inexpensive energy functions.

The cheapest in terms of CPU-time approach to treat the transition metal complexes is represented by the force field (FF) methods. ${ }^{62-66}$ In principle, even the standard and very general out-of-the-box FF methods, such as the universal force field (UFF) approximation, have been shown to perform reasonably well for conformational sampling of transition metal complexes. ${ }^{49}$ In cases where the UFF method is not sufficiently accurate, a few more FF-based strategies can be utilized. Thus, careful parameterization of both metal and functional groups can be done prior to the conformational search. ${ }^{56,58,65-70}$ However, the FF parameterization is a tedious task requiring expertise and can be time consuming. Therefore, this approach is not suitable for routine applications as in molecular screening, where the conformational sampling of thousands of molecules is required. In any case, parameterization of a FF is probably the most viable option in case of conformational search on a single transition metal complex with an immutable coordination sphere, or when large amount of structures has to be sampled. Another FF-related approach requiring less manual work is to fix the atoms comprising the transition metal coordination sphere either at their crystallographic or DFT positions, and run the conformational search on the organic "non-frozen" part of the complex. ${ }^{50,55,57,71-77}$ Semiempirical methods ${ }^{78-81}$ represent another out-of-the-box alternative to FF methods, albeit they are computationally more intensive, and have been successfully applied for decades in many areas of organic ${ }^{78-79,81-92}$ and to less extent transition metal chemistry. ${ }^{33}, 36,45,78-79,93-115$ Thus, PM3(TM) and PM6 semiempirical methods have been successfully used for conformational search on molybdenum, ${ }^{53-54}$ ruthenium, ${ }^{116}$ rhenium $^{49}$ and technetium ${ }^{51}$ systems. However, their accuracy 
for relative conformational energies have never been systematically tested for a series systems containing various transition metals. In addition, there is no single opinion on the preference of FF or semiempirical methods for the conformational search of transition metal species. Comparing FF and semiempirical methods to sample the conformational spaces of a series of technetium complexes, Buda et al. noted that in a number of cases semiempirical methods are more reliable than FFs, as the latter could not predict the right isomer. ${ }^{51}$ In contrast, Gillespie et al. $^{49}$ showed that a few potential energy minima found during molecular mechanics conformational search of rhenium complex have disappeared after re-optimization with semiempirical methods. Taken together these studies indicate that the conformational energy surface of particular complex apparently depends (sometimes strongly) on the particular method chosen for geometry optimization, hampering the reliable conformational search.

In the current work we seek to contribute to testing an accuracy of semiempirical methods and generate a database containing 10 very accurate relative conformational energies for each out of 27 realistic sized (ca. 100 atoms) TM complexes initially retrieved from the Cambridge Structural Database. ${ }^{117}$ The developed database was used to test relative conformational energies from widely available out-of-the-box semiempirical methods: PM6, ${ }^{112}$ PM6-D3, ${ }^{112,}{ }^{118}$ PM6$\mathrm{DH}+{ }^{112,}{ }^{119}$ PM6-DH2, ${ }^{112,}{ }^{120-121}$ PM6-DH2X, ${ }^{112,}{ }^{122}$ PM6-D3H4, ${ }^{12,}{ }^{123}$ PM6-D3H4X ${ }^{12,}, 124$ and $\mathrm{PM} 7^{113}$. The performance of all methods was carefully analyzed, the most difficult cases were identified and the origin of the failures discussed in detail.

\section{Computational Details}

\subsection{Selection of Complexes and Conformer Generation}


All the initial structures of the transition metal complexes studied in the present work have been retrieved from the Cambridge Structural Database (CSD). ${ }^{117}$ Pursuing the maximal diversity in our benchmark set we included complexes of 16 transition metals related to catalysis $(\mathrm{Au}, \mathrm{Cd}$, $\mathrm{Cr}, \mathrm{Hf}, \mathrm{Hg}$, Ir, Pd, Pt, Rh, Ru, Sc, Ti, V, W, Y, Zr) containing various functional groups and different covalent and non-covalent ligands. For each complex we have generated 10 conformers in total from the X-Ray structures as follows. First, the random values of the dihedral angles corresponding to the rotatable bonds had been set up and the preliminary structure was generated. Then, to avoid clashing, each structure was pre-optimized with UFF potential by keeping all the bonds and angle bends at their X-Ray values and relaxing only the dihedral angle values of the rotatable bonds. All the transition metal complexes studied in this work together with their CSD names are given in Figure 1. 


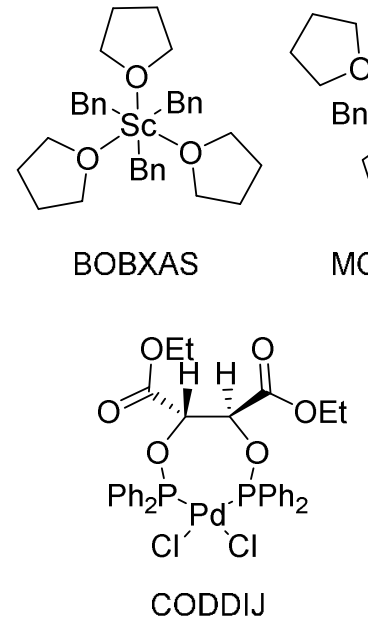

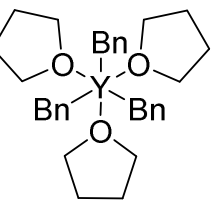

MOGWIP

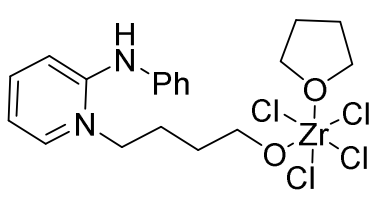

RESCUN

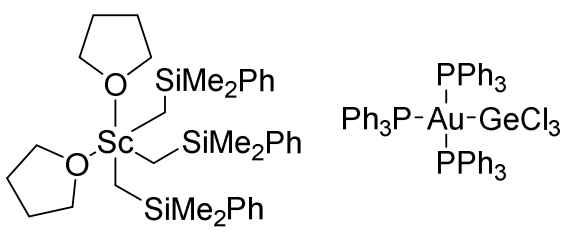

EGOZUV

TITVEX01

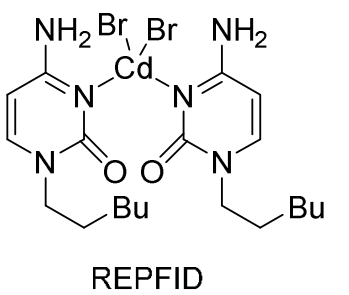

$$
\begin{aligned}
& \begin{array}{r}
\mathrm{C}_{6} \mathrm{~F}_{5}-\mathrm{B}_{-}-\mathrm{C}_{6} \mathrm{~F}_{5} \\
\mathrm{H}_{2} \mathrm{~N}^{-} \mathrm{C}_{6} \mathrm{~F}_{5}
\end{array} \\
& \mathrm{Et}_{2} \mathrm{~N}^{-\mathrm{Ti}} \mathrm{NEt}_{2}-\mathrm{NEt}_{2}
\end{aligned}
$$

SIGSUX
$\begin{array}{ll}\mathrm{Et}_{2} \mathrm{~N} & \mathrm{NEt}_{2} \\ \mathrm{Et}_{2} \mathrm{~N}-\mathrm{V} & \mathrm{C}_{6} \mathrm{~F}_{5} \\ \mathrm{~B} & -\mathrm{B}-\mathrm{C}_{6} \mathrm{~F}_{5} \\ \mathrm{C}_{6} \mathrm{~F}_{5}\end{array}$

LUWRUQ

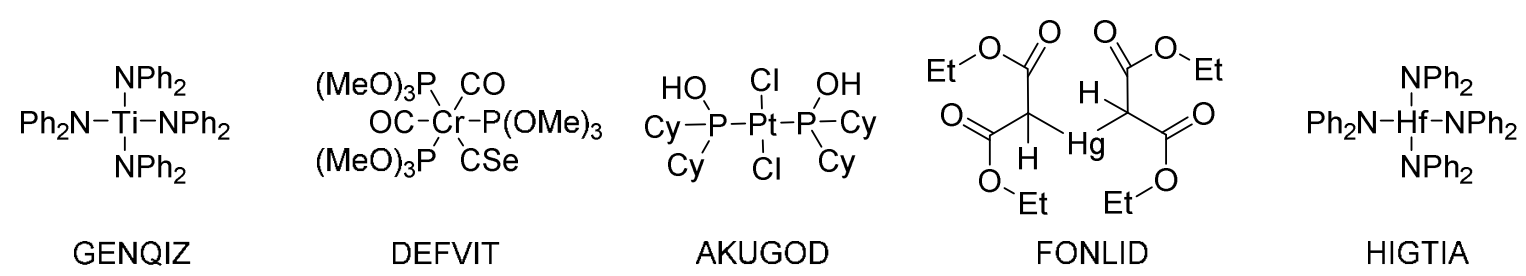

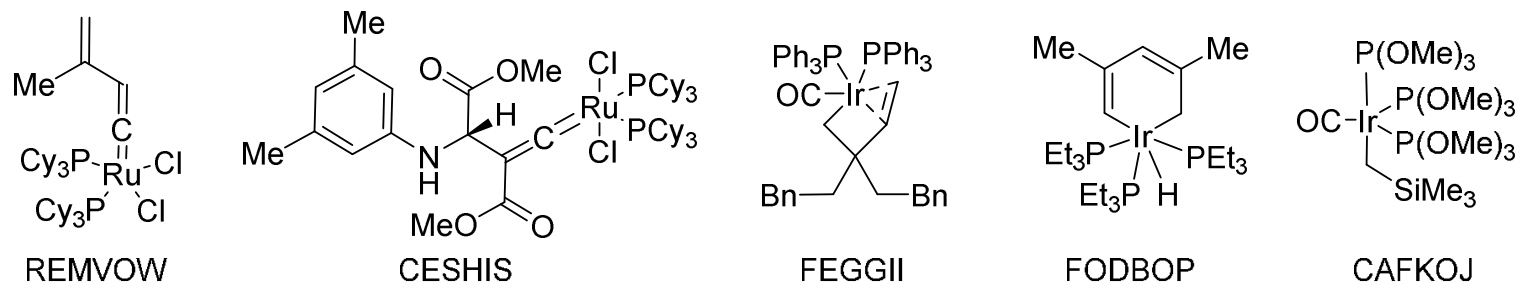<smiles>Cc1cc(C)c(N2C=CN(c3c(C)cc(C)cc3C)C2C(Cl)(Cl)N2C=CN(CCNC(=O)c3ccccc3)C2C)c(C)c1</smiles>

LEHJAL

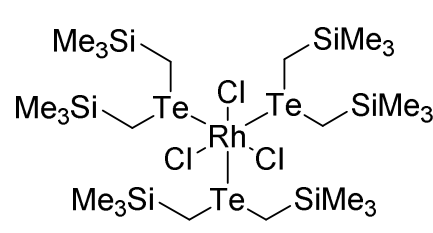

DUGVEH<smiles>CCCN(C(=O)Cl)N(c1ccccc1)N(c1ccccc1)N(c1ccccc1)c1ccccc1</smiles>

ABAKOE

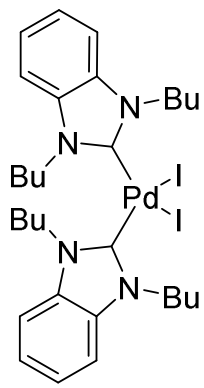

MIYBAZ<smiles>COc1ccc([Te](CCN2CCOCC2)[Te](Cl)(Cl)[Te](Cl)(Cl)c2ccc(OC)cc2)cc1</smiles>

WOWSAC<smiles>N[P+](Cl)(Cl)(NCCNC(=O)NCCN1C(=O)C=CC1=O)OC(=O)NCCN1C(=O)C=CC1=O</smiles>

BESJAM

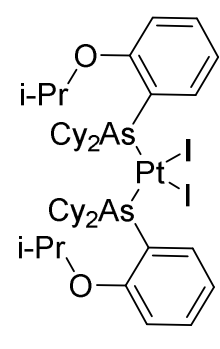

LARJIZ

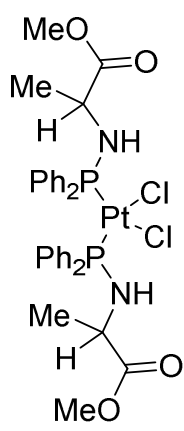

DILQAQ 
Figure 1. Transition metal complexes studied in this work together with their Cambridge Structural Database (CSD) names.

\subsection{Technical Protocols Utilized to Derive and Compare the Conformational Energies}

\subsubsection{Strategy I}

In the first part of the study all geometry optimizations of the generated conformers (see Section 2.1) were performed with the local GGA PBE ${ }^{125-126}$ functional as implemented in Gaussian $09^{127}$ suite of programs as this method was found to accurately reproduce the molecular spatial structures of inorganic species. ${ }^{34,128-132}$ The Grimme's D3(BJ) ${ }^{118}$ dispersion correction was applied to arrive at the PBE-D3(BJ) functional, to account the possible influence of the noncovalent interaction not covered by standard PBE functional on molecular geometries. ${ }^{133-135}$ The default values were adopted for the self-consistent-field (SCF) and geometry optimization convergence criteria. Numerical integration of the exchange-correlation (XC) terms was performed using tighter-than-default "ultrafine" option (pruned, 99 radial shells and 590 angular points per shell) to eliminate the potential numerical noise in energy second derivatives. Geometries were characterized as true energy minima by the eigenvalues of the analytically calculated Hessian matrix.

The all-electron double- $\zeta$ basis sets accomplished with single sets of polarization functions ("def2-svp") of Ahlrichs et al. ${ }^{136}$ were used on all the elements with $Z \leq 36$. On all the elements with $\mathrm{Z}>36$ to account for the scalar relativistic effects the Stuttgart-type effective core potentials ${ }^{137}$ were used to describe the inner (28 electrons on $\mathrm{Sn}, \mathrm{Cd}, \mathrm{Pd}, \mathrm{I}, \mathrm{Te}, \mathrm{Rh}, \mathrm{Ru}, \mathrm{Y}$ and $\mathrm{Zr}$, 60 electrons on $\mathrm{Au}, \mathrm{Hf}, \mathrm{Hg}, \mathrm{Ir}, \mathrm{W}$ and $\mathrm{Pt}$ ) electrons in combination with corresponding def2-svp 
basis set. ${ }^{136}$ The density fitting algorithms with automatic generation of the auxiliary basis sets were turned on by "Auto" Gaussian 09 keyword to speed up the calculations.

The single-point energy evaluations on the structures obtained after geometry optimizations were performed with the hybrid-meta-GGA M06 functional as implemented in Gaussian 09. Alike in the geometry optimization procedure, numerical integration of the exchange-correlation (XC) terms was performed using "ultrafine" grid to eliminate the potential numerical noise in electronic energy. ${ }^{138-139}$ The all-electron triple- $\zeta$ basis sets accomplished with single set of polarization functions ("def2-tzvp") of Ahlrichs et al. ${ }^{136}$ were used on all the elements with $\mathrm{Z} \leq$ 36. On all the elements with $Z>36$ to account for the scalar relativistic effects the Stuttgart-type effective core potentials ${ }^{137}$ were used to describe the inner electrons (28 electrons on $\mathrm{Sn}, \mathrm{Cd}, \mathrm{Pd}$, I, Te, $\mathrm{Rh}, \mathrm{Ru}, \mathrm{Y}$ and $\mathrm{Zr}, 60$ electrons on $\mathrm{Au}, \mathrm{Hf}, \mathrm{Hg}$, Ir, Os and $\mathrm{Pt}$ ) in combination with corresponding def2-tzvp basis set. ${ }^{136}$

Thus obtained conformational energies have been used as references and are denoted as M06/def2-tzvp//PBE-D3/def2-svp. To show that thus obtained relative conformational energies are not sensitive to the choice of particular DFT method, we have performed a series of additional SP energy calculations with PBE0-D3 method and def2-tzvp basis set abbreviated further as PBE0-D3/def2-tzvp//PBE-D3/def2-svp. In addition, to explore the basis set effect, the M06/def2-tzvp//PBE-D3/def2-svp relative conformational energies have been systematically compared with those derived from geometry optimization method, PBE-D3/def2-svp. Notably, practically in all cases the PBE0-D3/def2-tzvp//PBE-D3/def2-svp and PBE-D3/def2-svp conformational energies were found to practically mimic their M06/def2-tzvp//PBE-D3/def2-svp counterparts. 
Finally, the SP energies on the optimized PBE-D3 conformers were calculated with out-of-thebox semiempirical PM6, ${ }^{112}$ PM6-D3, ${ }^{112,} 118$ PM6-DH+, ${ }^{112,} 119$ PM6-DH2, ${ }^{112,}$ 120-121 PM6$\mathrm{DH} 2 \mathrm{X},{ }^{112,}{ }^{122} \mathrm{PM} 6-\mathrm{D} 3 \mathrm{H} 4,{ }^{112,123} \mathrm{PM} 6-\mathrm{D} 3 \mathrm{H} 4 \mathrm{X}^{112,124}$ and $\mathrm{PM} 7^{113}$ methods as implemented in MOPAC electronic structure package. ${ }^{140}$

\subsubsection{Strategy II}

In the second part of the work each structure generated in Section 2.1 and optimized with PBED3/def2-svp protocol as outlined in Section 2.2.1 has been re-optimized with $\mathrm{PM}^{113}$ semiempirical method as implemented in MOPAC electronic structure package. ${ }^{140}$ All the default MOPAC internal values were used apart from the geometry optimization termination criterion GNORM, for which the default value of $1 \mathrm{kcal} \cdot \mathrm{mol}^{-1} / \AA$ was decreased to $0.1 \mathrm{kcal} \cdot \mathrm{mol}^{-}$ $1 / \AA$ to ensure more precisely optimized structures. The two geometry optimization strategies were used for optimizing the conformers. In the first strategy, the "non-constrained" geometry optimization has been performed with the positions of all the atoms relaxed during the optimization process. In the second strategy, usual for routine conformational search in the transition metal catalysis, the "constrained" geometry optimization has been performed with fixed (at their PBE-D3/def2-svp values) positions of transition metal and bonded to transition metal atoms to preserve the structure of the coordination center. In addition, the positions (Cartesian coordinates) of few more atoms constituting several functional groups directly bonded to transition metal were kept fixed in some complexes at their DFT positions as well: $\mathrm{GeCl}_{3}$ group in TITVEX01 $\left(\mathrm{Ph}_{3} \mathrm{P}\right)_{3} \mathbf{A u G e C l}_{3}, \mathrm{CSe}$ group in DEFVIT $\left[(\mathrm{MeO})_{3} \mathrm{P}\right]_{3} \mathbf{C r}(\mathrm{CO})_{2}(\mathrm{CSe})$, and

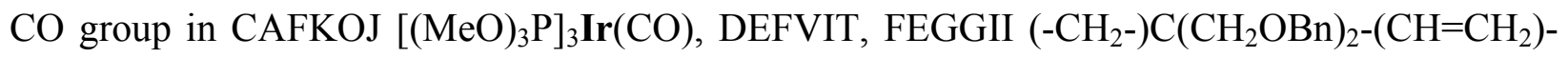
$\operatorname{Ir}\left(\mathrm{PPh}_{3}\right)_{2}(\mathrm{CO})$. 
In both PM7 optimization strategies after the PM7 relative energies for each conformers were derived and tabulated, each conformer was again re-optimized with PBE-D3 method (as in Section 2.2.1) and M06 and PBE0-D3 SP energies with def2-tzvp basis sets were calculated to derive the relative conformational energies as it was done in Section 2.2.1.

\subsection{Comparing the Conformational Energies}

Few quantitative criteria have been used to compare the semiempirical conformational energies with their reference values.

\subsubsection{Calculation of Pearson Correlation Coefficient}

To quantify the correlation between conformational energies from semiempirical computational chemistry methods, PBE0-D3/def2-tzvp//PBE-D3/def2-svp and PBE-D3/def2-svp protocols with reference M06/def2-tzvp//PBE-D3/def2-svp conformational energies, we have calculated the Pearson correlation coefficient $(\rho)$ and the squared version thereof $\left(\rho^{2}\right)$.

The following formula was used to calculate the Pearson correlation coefficient:

$\rho(X, Y)=\frac{\sum_{i=1}^{n}\left(E_{x, i}-\bar{E}_{x}\right)\left(E_{y, i}-\bar{E}_{y}\right)}{\sqrt{\sum_{i=1}^{n}\left(E_{x, i}-\bar{E}_{x}\right)^{2} \sum_{i=1}^{n}\left(E_{y, i}-\bar{E}_{y}\right)^{2}}}$

where $\mathrm{X}$ is the tested electronic structure theory method to obtain the conformational energies and $\mathrm{Y}$ is the method to obtain the reference conformational energies, i.e. M06/def2-tzvp//PBE0D3/def2-svp, $\mathrm{n}$ is the number of conformations calculated for a given transition metal complex, $E_{i}$ is the conformational energy of $\mathrm{i}^{\text {th }}$ conformer, and $\bar{E}$ is the average conformational energy for $\mathrm{n}$ conformers from a given method. The $\rho$ coefficient can occupy any value in the interval $[-1$, 
+1 ]. If the $\rho$ value is close to 1 there is an absolute correlation, and if this value is close to -1 there is an anti-correlation.

The squared Pearson correlation coefficient $\left(\rho^{2}\right)$ is obtained straightforwardly from Eq. 1 and can be any value in the interval $[0,1]$. While the $\rho^{2}$ is the most popular criterion in the field of chemoinformatics to quantitatively measure the correlation $\left(\rho^{2} \geq 0.95\right.$ indicates excellent correlation), it can be misleading when describing the quality of the conformational energies from a certain method as it is always positive and cannot distinguish between correlation and anti-correlation. In particular, the large (close to 1) $\rho^{2}$ values can correspond to both correlation $(\rho \approx 1)$ and anti-correlation $(\rho \approx-1)$.

\subsubsection{Calculation of the Mean Unsigned Deviations in Conformational Energies}

Another criterion to judge the quality of the relative conformational energies is to calculate the mean absolute deviation (MUD) between the relative energies obtained with particular method and corresponding reference values (M06/def-tzvp//PBE-D3/def2-svp). The following formula was used to calculate the mean absolute deviation of particular complex:

$\operatorname{MUD}($ Complex $)=\frac{\sum_{i=0}^{n}\left|E_{i}(X)-E_{i}(Y)\right|}{n}$

Where $\mathrm{X}$ is the tested method, $\mathrm{Y}$ is the reference method (M06/def-tzvp//PBE-D3/def2-svp), $\mathrm{n}$ is the number of conformers calculated for the certain complex and $E_{\mathrm{i}}$ is the relative energy of the conformer i.

\section{Results and Discussion}


The results and discussion is organized as follows. First, following the Strategy I, we explored the potential energy surface (PES) from several electronic structure theory methods. For each structure/conformer in our dataset we compared the relative conformational energies retrieved from the semiempirical, PBE-D3/def2-svp, PBE0-D3/def2-tzvp and M06/def2-tzvp SP energies on the PBE-D3 optimized geometries. Second, following the Strategy II, we estimated the potential errors arising from the conformational search based on geometry optimization with semiempirical methods. We performed geometry optimizations with PM7 method of all the conformers generated in the previous step followed by subsequent PBE-D3/def2-svp geometry optimizations and PBE0-D3/def2-tzvp and M06/def2-tzvp SP energy evaluations. Finally, the results are analyzed, the possible origins of the largest deviations are discussed, and conclusions on the applicability of the semiempirical methods for the conformational search and sampling in the realistic-size transition metal complexes are given.

\subsection{Comparing the Relative Conformational Energies Using Strategy I}

The averaged over all the complexes $\rho^{2}$ and $\rho$ (Pearson correlation coefficient) values of conformational energies derived from the SP energies obtained with all the methods tested on the PBE-D3/def2-svp geometries with respect to the reference M06/def2-tzvp values are given in Figures 2 and 3. In addition, the lowest and highest $\rho^{2}$ and $\rho$ values are also given in the Figures through the solid lines to have an idea of the span.

As can be seen from Figure 2, an average PBE0-D3/def2-tzvp and PBE-D3/def2-svp $\rho^{2}$ values turned out to be 0.97 and 0.93 , indicating rather strong correlation. Quite large average $\rho^{2}$ numbers and an absence of any negative $\rho$ values for any complex studied in the present work indicate DFT methods to be quite robust in predicting the relative conformational energies. It 
suggests the M06/def2-tzvp//PBE-D3/def2-svp protocol to be the reliable source of relative conformational energies, and we do not expect any significant changes upon change in the reference SP and geometry optimization method with any other contemporary DFT method accomplished with the basis set of reasonable quality.

Remarkably, for all tested semiempirical methods significantly lower average $\rho^{2}$ values all below 0.55 have been obtained. The lowest average values of 0.45 and 0.47 were obtained for PM7 and PM6 methods, correspondingly. The highest average value of 0.55 were obtained for PM6-D3H4 and PM6-D3H4X methods, indicating only insignificant difference between the best and the worth performers. The performance of the semiempirical methods is heterogeneous and varies from complex to complex which is reflected in the large span between the largest and lowest $\rho^{2}$ values. Thus, for the most recent PM7 method the smallest $\rho^{2}$ value of only 0.02 has been obtained for DEFVIT complex $\left[(\mathrm{MeO})_{3} \mathrm{P}\right]_{3} \mathbf{C r}(\mathrm{CO})_{2}(\mathrm{CSe})$ indicating practically no correlation. Meanwhile, quite high $\rho^{2}$ value of 0.93 was obtained for complexes FONLID $\mathbf{H g}\left[\mathrm{CH}(\mathrm{COOEt})_{2}\right]_{2}$ and DUGVEH $\left[\left(\mathrm{Me}_{3} \mathrm{SiCH}_{2}\right)_{2} \mathrm{Te}\right]_{3} \mathbf{R h C l}{ }_{3}$ which is comparable to DFT performance.

Another striking difference comparing to the tested DFT methods is existing of negative $\rho$ values which, according to Figure 3, have been detected for all the semiempirical methods indicating signs of anti-correlation in some cases. For example, for PM7 method negative $\rho$ value was obtained for 6 out of 27 complexes:TITVEX01 $\left(\mathrm{Ph}_{3} \mathrm{P}\right)_{3} \mathbf{A u G e C l}_{3} \quad(\rho=-0.48)$, CAFKOJ $\left[(\mathrm{MeO})_{3} \mathrm{P}\right]_{3} \mathbf{I r}(\mathrm{CO}) \quad(\rho=-0.42), \quad$ AKUGOD $\quad\left[(\mathrm{Cy})_{2} P-\mathrm{OH}\right]_{2} \mathbf{P t C l}_{2} \quad(\rho=-0.42), \quad$ BOBXAS $(\mathrm{Bn})_{3} \mathbf{S e}(\text { Furan })_{3}(\rho=-0.48)$, GENQIZ Ti( $\left.\mathrm{NPh}_{2}\right)_{4}(\rho=-0.40)$ and MOGWIP $(\mathrm{Bn})_{3} \mathbf{Y}(\text { Furan })_{3}(\rho=-$ $0.18)$. 


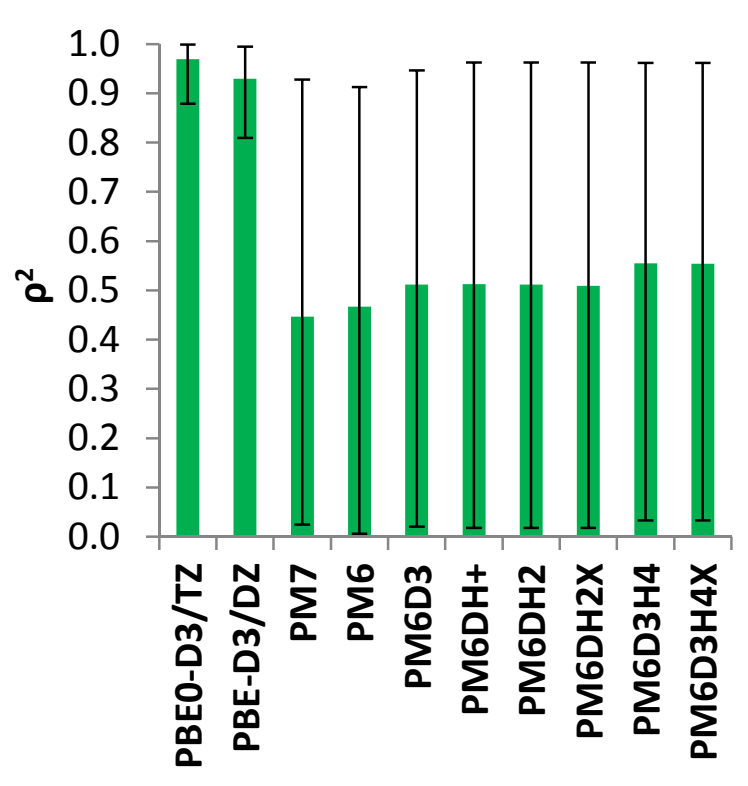

Figure 2. The $\rho^{2}$ (the squared Pearson correlation coefficient) values obtained for correlation between single-point (SP) energy-based DFT (PBE0-D3/def2-tzvp and PBE-D3/def2-svp) and semiempirical (PM6, PM6-D3, PM6-DH+, PM6-DH2, PM6-DH2X, PM6-D3H4, PM6-D3H4X and PM7) relative conformational energies and their corresponding references (M06/def2-tzvp) for transition metal complexes studied in the present work. The solid bars indicate the average values, and the ends of the solid lines at each bar give the lowest and the highest values. 


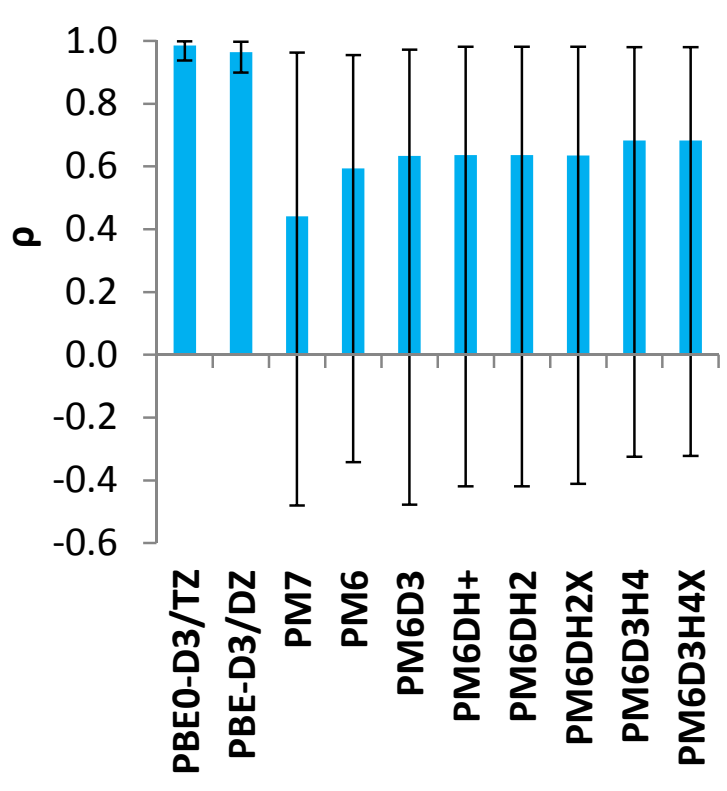

Figure 3. The $\rho$ (the Pearson correlation coefficient) values obtained for correlation between single-point (SP) energy-based DFT (PBE0-D3/def2-tzvp and PBE-D3/def2-svp) and semiempirical (PM6, PM6-D3, PM6-DH+, PM6-DH2, PM6-DH2X, PM6-D3H4, PM6-D3H4X and PM7) relative conformational energies and their corresponding references (M06/def2-tzvp) for transition metal complexes studied in the present work. The solid bars indicate the average values, and the ends of the solid lines at each bar give the lowest and the highest values.

To explore the quality of the absolute values of the relative conformational energies important for reliable Boltzmann distribution, for each complex we calculated the mean absolute deviations (MUDs) between conformational energies obtained with tested method and their reference (M06/def2-tzvp) counterparts. The results are summarized in Figure 4. 


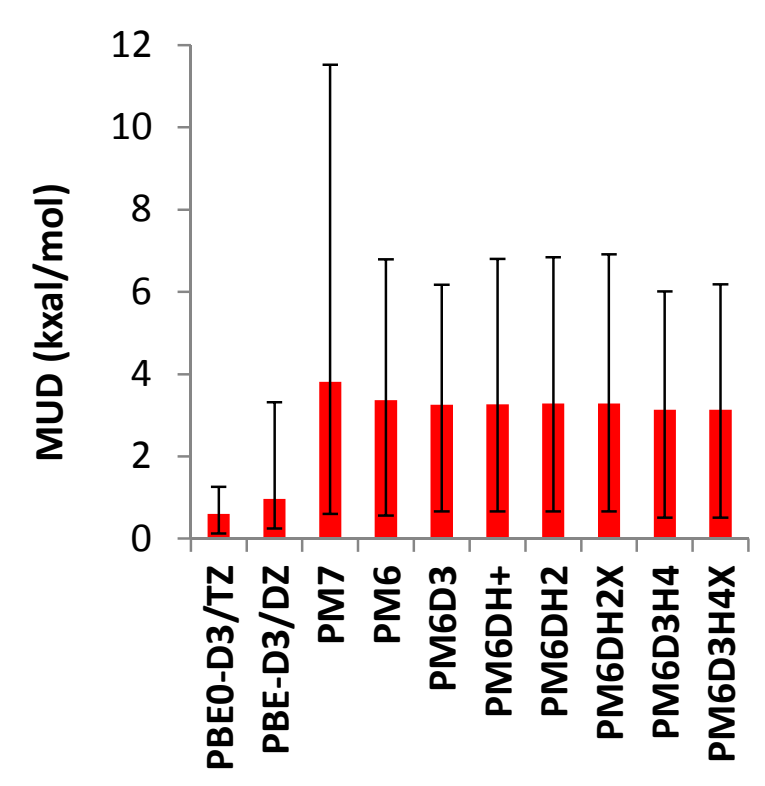

Figure 4. The mean unsigned deviation (MUD) values obtained between reference M06/def2tzvp reference conformational energies and their PBE0-D3/def2-tzvp, PBE-D3/def2-svp, semiempirical (PM6, PM6-D3, PM6-DH+, PM6-DH2, PM6-DH2X, PM6-D3H4, PM6-D3H4X and PM7) counterparts for transition metal complexes studied in the present work. The solid bars indicate the average MUD values, and the ends of the solid lines at each bar give the lowest and the highest MUD values obtained for particular complexes.

For the PBE0-D3/def2-tzvp method the average MUD turned out to be $0.6 \mathrm{kcal} / \mathrm{mol}$. The PBED3/def2-svp method with an average MUD of $1.0 \mathrm{kcal} / \mathrm{mol}$ is only slightly less accurate. Significantly larger MUDs in range 3.1 (PM6-D3H4 and PM6-D3H4X) to 3.8 (PM7) kcal/mol have bene obtained for semiempirical methods. Comparing to DFT methods, notably larger variations in MUD values have been obtained from complex to complex. Thus, the largest PM7 MUD of $11.5 \mathrm{kcal} / \mathrm{mol}$ was obtained for CAFKOJ complex $\left[(\mathrm{MeO})_{3} \mathrm{P}\right]_{3} \mathbf{I r}(\mathrm{CO})$ and the lowest MUD of $0.6 \mathrm{kcal} / \mathrm{mol}$ was obtained for FONLID complex $\mathbf{H g}\left[\mathrm{CH}(\mathrm{COOEt})_{2}\right]_{2}$. Combined with respective $\rho^{2}$ and $\rho$ tests, the results indicate quite heterogeneous performance in reproducing of 
the reference conformational energies: good performance for some complexes alternates with spectacular failures for others. ${ }^{52}$

\subsection{Comparing the Relative Conformational Energies Using Strategy II}

Since the semiempirical methods sometimes fail to reproduce the coordination center of transition metal complexes even qualitatively, we performed the PM7 geometry optimizations in the two ways: with relaxation of all parameters (unconstrained geometry optimization) and with fixed atomic positions of the coordination center atoms, see Computational details section 2.2.2.

\subsubsection{Unconstrained Geometry Optimization}

The $\rho^{2}$ and $\rho$ values between PM7//PM7 and M06-def2-tzvp//PBE-D3/def2-svp relative conformational energies are presented in Figure 5. The average $\rho^{2}$ value obtained for all 27 structures turned out to be 0.41 which is reasonably close to PM7 $\rho^{2}$ value of 0.45 obtained based exclusively on SP energies. An average $\rho$ value turned out to be 0.25 which is smaller than that of 0.44 based on the SP energies. The largest $\rho^{2}$ values followed by positive $\rho$ values have been detected for TITVEX01 $\left(\mathrm{Ph}_{3} \mathrm{P}\right)_{3} \mathbf{A u G e C l}_{3} \quad\left(\rho^{2} / \rho=0.85 / 0.92\right)$, REPFID (HexylCyt $)_{2} \mathbf{C d B r}_{2}$ $\left(\rho^{2} / \rho=0.80 / 0.89\right), \quad$ FONLID $\quad \mathbf{H g}\left[\mathrm{CH}(\mathrm{COOEt})_{2}\right]_{2} \quad\left(\rho^{2} / \rho=0.90 / 0.95\right), \quad$ DILQAC $\left[\mathrm{MeOC}(\mathrm{O}) \mathrm{CH}(\mathrm{Me}) \mathrm{NH}-\mathrm{PPh}_{2}\right]_{2} \mathbf{P t C l}_{2}\left(\rho^{2} / \rho=0.83 / 0.91\right)$ and DUGVEH $\left[\left(\mathrm{Me}_{3} \mathrm{SiCH}_{2}\right)_{2} \mathrm{Te}_{3} \mathbf{R h C l} \mathbf{R}_{3}\right.$ $\left(\rho^{2} / \rho=0.81 / 0.90\right)$ indicating correlation. In contrast, large $\rho^{2}$ value followed by negative $\rho$ value was obtained for REMVOW [propen-2-yl]-CH=C=Ru( $\left.\mathrm{PCy}_{3}\right)_{2} \mathrm{Cl}_{2}\left(\rho^{2} / \rho=0.83 /-0.91\right)$ indicating the anti-correlation, and making black-box application of PM7 method for this complex dangerous. 


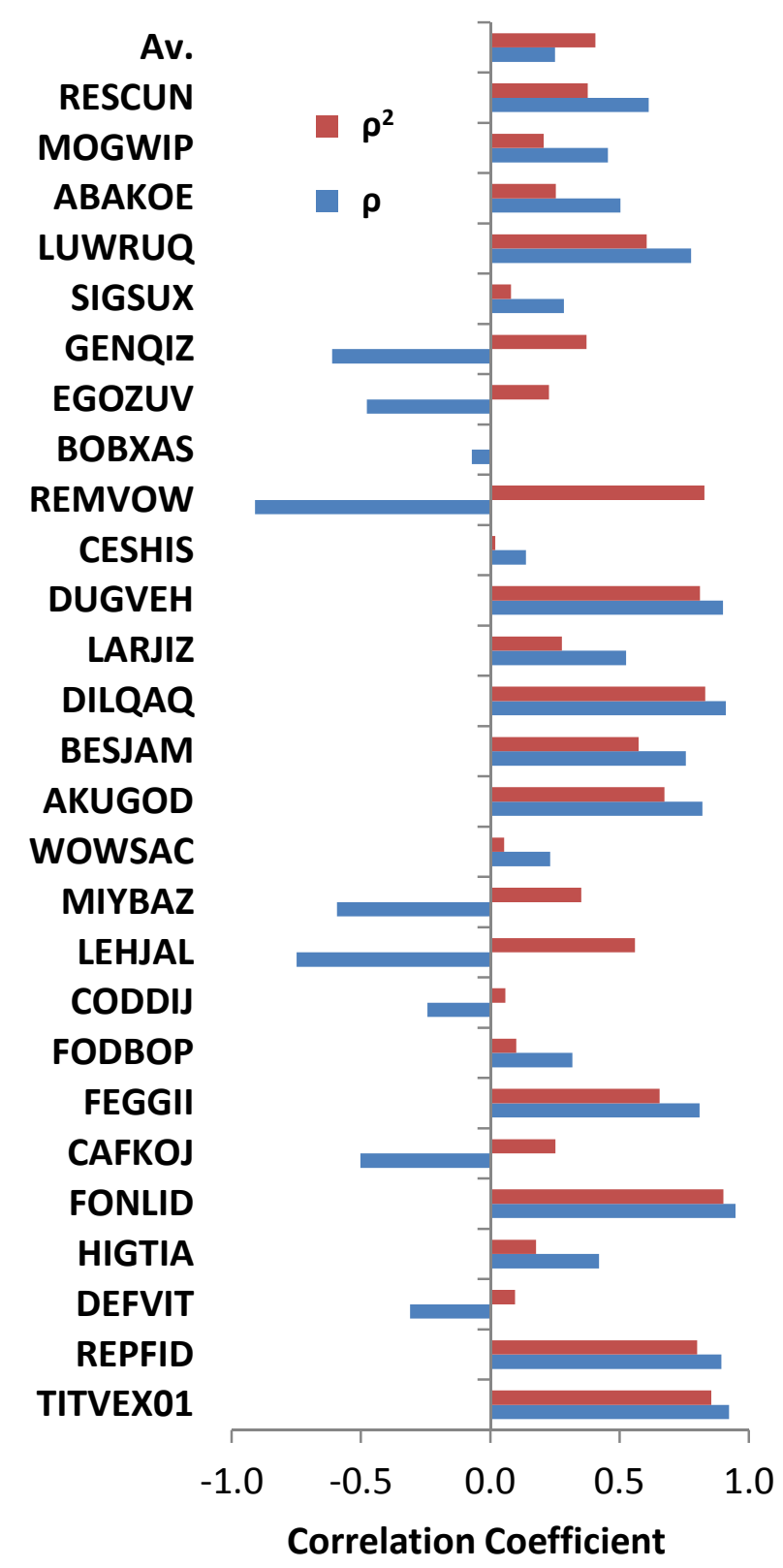

Figure 5. The $\rho^{2}$ and $\rho$ correlation coefficients obtained between PM7 relative conformational energies on PM7 geometries and M06/def2-tzvp relative conformational energies on PBED3/def2-svp optimized geometries with PM7 optimized geometries used as starting point. 


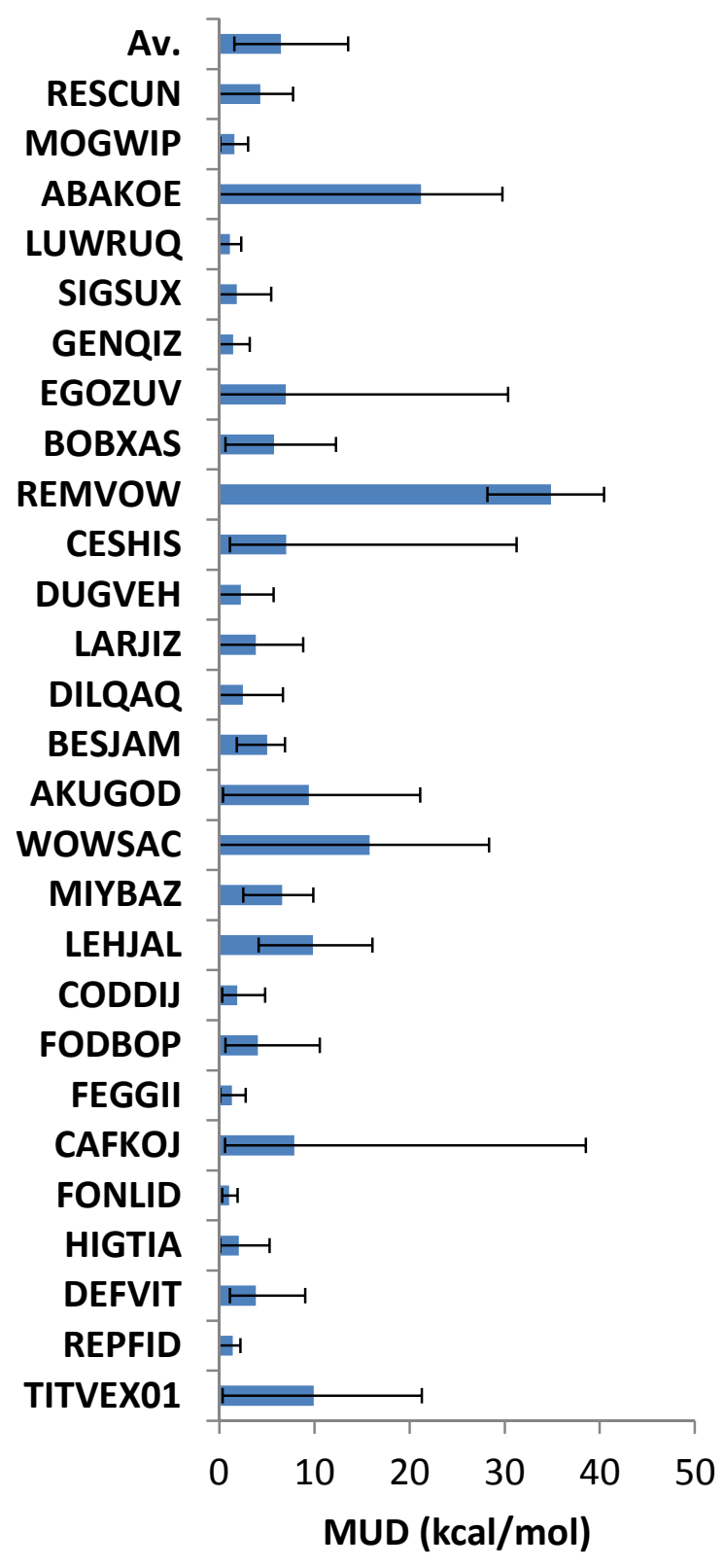

Figure 6. The mean unsigned deviation (MUD) values obtained between the PM7//PM7 and M06/def2-tzvp//PBE-D3//def2-svp relative conformational energies for transition metal complexes studied in the present work. The solid bars indicate the average MUD value, and the ends of the solid lines at each bar give the lowest and the highest absolute deviation obtained for particular complexes. 
In Figure 6 the MUDs obtained between PM7//PM7 and M06/def2-tzvp//PBE-D3/def2-svp conformational energies are presented for each complex together with the largest and lowest absolute deviations in the relative conformational energies. The average MUD turned out to be $6.5 \mathrm{kcal} / \mathrm{mol}$. The lowest MUD of $1.0 \mathrm{kcal} / \mathrm{mol}$ has been obtained for complex FONLID $\mathbf{H g}\left[\mathrm{CH}(\mathrm{COOEt})_{2}\right]_{2}$ and the largest MUD of $34.9 \mathrm{kcal} / \mathrm{mol}$ has been obtained for REMVOW [propen-2-yl]-CH=C= $\mathbf{R u}\left(\mathrm{PCy}_{3}\right)_{2} \mathrm{Cl}_{2}$.

The manual inspection of all the optimized geometries revealed incorrect PM7 coordination center geometries of some structures to be responsible for the PM7 failures. One particular example is conformer 5 of ruthenium complex REMVOW [propen-2-yl]- $\mathrm{CH}=\mathrm{C}=\mathbf{R u}\left(\mathrm{PCy}_{3}\right)_{2} \mathrm{Cl}_{2}$. As depicted in Figure 7, PM7 geometry optimization of this structure resulted in $\mathrm{Cl}$ migration from $\mathrm{Ru}$ atom to carbon atom bonded to $=\mathrm{C}$ group of ruthenium took place manifesting chemical transformation. The subsequent PBE-D3/def2-svp optimization did not return $\mathrm{Cl}$ atom back to $\mathrm{Ru}$ to lead to initial structure. In contrast to conformer 5, all other conformers of REMVOW did not undergo to chemical transformation upon PM7 optimization. Similarly, the chemical transformation occurred upon PM7 geometry optimization of some (or all) conformers turned out to be responsible for large energy deviations obtained for other complexes, in particular for TITVEX01 $\left(\mathrm{Ph}_{3} \mathrm{P}\right)_{3} \mathbf{A u G e C l}_{3}\left(\mathrm{GeCl}_{3}\right.$ group dissociation from Au, see Figure S1), FODBOP [$\mathrm{CH}=\mathrm{CMe}-\mathrm{CH}=\mathrm{CMe}-]>\mathbf{I r}(\mathrm{H})\left(\mathrm{PEt}_{3}\right)_{3}\left(\mathrm{CH}_{2}\right.$ dissociation from Ir for conformer 6, see Figure S2), LEHJAL $\left[\mathrm{C}_{21} \mathrm{H}_{34} \mathrm{~N}_{3} \mathrm{O}\right]_{2} \mathbf{P d C l} l_{2}$ (coordination of the two hydrogen atoms to Pd, see Figure $\mathrm{S} 3$ ), MIYBAZ [N,N-diBu-benzimidazoline $]_{2} \mathbf{P d I} I_{2}$ (coordination the $\mathrm{CH}_{2}$ groups to $\mathrm{Pd}$, i.e. change square planar to octahedral configuration, see Figure S4), WOWSAC [MeOPh-Te- $\left(\mathrm{CH}_{2}\right)_{2}$ Morpholinyl $]_{2} \mathbf{P d C l}{ }_{2}$ (hydrogen coordination to Pd, see Figure S5), CAFKOJ $\left[(\mathrm{MeO})_{3} \mathrm{P}\right]_{3} \mathbf{I} \mathbf{r}(\mathrm{CO})$ 
(OMe transfer from P to Ir for conformer 8, see Figure S6), EGOZUV (Furan $)_{2} \mathrm{Sc}\left(\mathrm{CH}_{2} \mathrm{SiMe}_{2} \mathrm{Ph}\right)_{3}$ (dissociation of the two (conformer 2) or one (conformer 5) THF molecules from Sc, Figure S7), CESHIS $\left[\mathrm{C}_{14} \mathrm{H}_{17} \mathrm{NO}_{4}\right]=\mathrm{C}=\mathbf{R u}\left(\mathrm{PCy}_{3}\right)_{2} \mathrm{Cl}_{2}(\mathrm{Cl}$ transfer from $\mathrm{Ru}$ to $=\mathrm{C}$ group for conformer 9 , see Figure S8). At the same time, correctly reproduced coordination center geometry does not guarantee accurate relative conformational energies, as in case of ABAKOE (Ph- $N-$ $\mathrm{iPr})_{3} \mathbf{W}(=\mathrm{O}) \mathrm{Cl}$.

An analysis of Figures 5 and 6 combined with manual geometries checks suggests that only for a few (e.g. FONLID $\left.\mathbf{H g}\left[\mathrm{CH}(\mathrm{COOEt})_{2}\right]_{2}, \mathrm{REPFID}(\mathrm{HexylCyt})_{2} \mathbf{C d B r}_{2}, \mathrm{LUWRUQ}_{(\mathrm{Et}} \mathrm{N}\right)_{3} \mathbf{V}=\mathrm{O}-$ $\left.\mathrm{B}\left(\mathrm{C}_{6} \mathrm{~F}_{5}\right)_{3}\right)$ out of 27 structures PM7 method can be used to obtain the reliable conformational energies and molecular geometries.

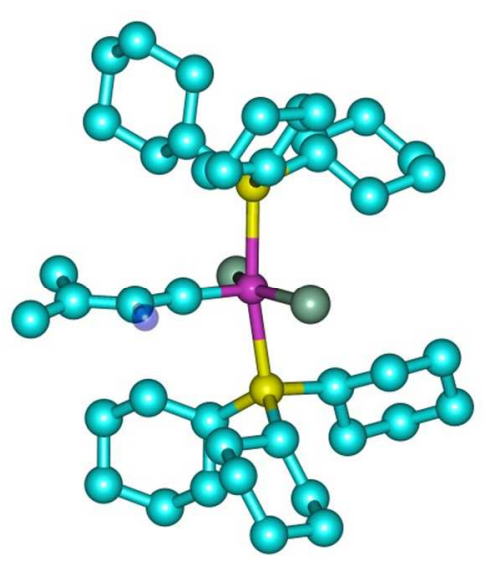

DFT

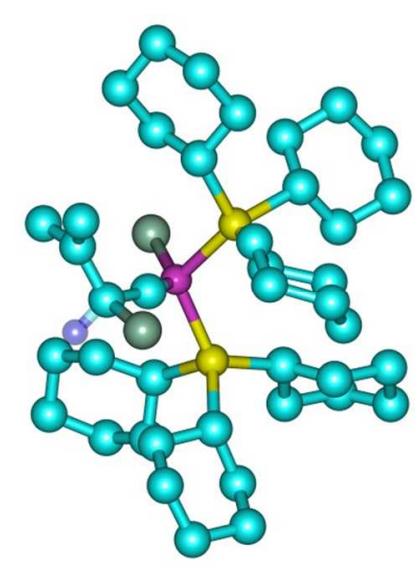

PM7

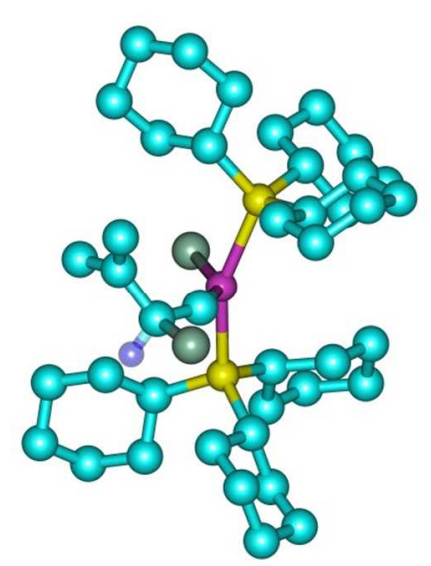

DFT

Figure 7. The molecular geometries of conformer 5 of REMVOW complex [propen-2-yl]$\mathrm{CH}=\mathrm{C}=\mathbf{R u}\left(\mathrm{PCy}_{3}\right)_{2} \mathrm{Cl}_{2}$ : initial PBE-D3 optimized conformer (left), the same conformer after PM7 geometry optimization (middle), the PM7 structure after subsequent PBE-D3 optimization 
(right). Color coding: Ru (Orchid), $\mathrm{Cl}$ (Aquamarine), C (Turquoise), P (Orange). Hydrogens of high importance are transparent blue, otherwise - omitted for clarity.

\subsubsection{Geometry Optimization with Fixed Coordination Center}

To see whether the constrained geometry optimization with all the atoms forming coordination center fixed at their DFT positions will improve on PM7 performance, we re-optimized all the PBE-D3 conformers obtained in Part I according to the procedure described in Section 2.2.2. The $\rho^{2}$ and $\rho$ values for correlation between PM7//PM7 and M06/def2-tzvp//PBE-D3/def2-svp relative conformational energies are presented in Figure 8. The average $\rho^{2}$ value obtained for all 27 structures turned out to be 0.46 which is practically identical to PM7 $\rho^{2}$ value of 0.45 obtained based on only SP energies (Part I). An average $\rho$ value turned out to be 0.37 which is reasonably close to PM7 $\rho$ value of 0.44 based on the SP energies and is higher than PM7 $\rho$ value of 0.25 obtained upon completely unrelaxed PM7 geometry optimizations. The largest $\rho^{2}$ values followed by positive $\rho$ values have been obtained for REPFID (HexylCyt $)_{2} \mathbf{C d B r}_{2}$ $\left(\rho^{2} / \rho=0.77 / 0.88\right)$, FONLID Hg[CH(COOEt $\left.)_{2}\right]_{2}\left(\rho^{2} / \rho=0.89 / 0.95\right)$, FEGGII $\left(-\mathrm{CH}_{2-}\right) \mathrm{C}_{\left(\mathrm{CH}_{2} \mathrm{OBn}\right)_{2}-}$ $\left(\mathrm{CH}=\mathrm{CH}_{2}\right)-\mathbf{I r}\left(\mathrm{PPh}_{3}\right)_{2}(\mathrm{CO}) \quad\left(\rho^{2} / \rho=0.81 / 0.90\right), \quad$ FODBOP $\quad[-\mathrm{CH}=\mathrm{CMe}-\mathrm{CH}=\mathrm{CMe}-]>\mathbf{I r}(\mathrm{H})\left(\mathrm{PEt}_{3}\right)_{3}$ $\left(\rho^{2} / \rho=0.83 / 0.91\right), \quad$ DUGVEH $\quad\left[\left(\mathrm{Me}_{3} \mathrm{SiCH}_{2}\right)_{2} \mathrm{Te}\right]_{3} \mathbf{R h C l}_{3} \quad\left(\rho^{2} / \rho=0.85 / 0.92\right) \quad$ and $\quad$ CESHIS $\left[\mathrm{C}_{14} \mathrm{H}_{17} \mathrm{NO}_{4}\right]=\mathrm{C}=\mathbf{R u}\left(\mathrm{PCy}_{3}\right)_{2} \mathrm{Cl}_{2} \quad\left(\rho^{2} / \rho=0.92 / 0.961\right)$ indicating correlation. No large $\rho^{2}$ values followed by negative $\rho$ values were obtained, indicating certain improvement upon fixed coordination center geometry optimizations. 


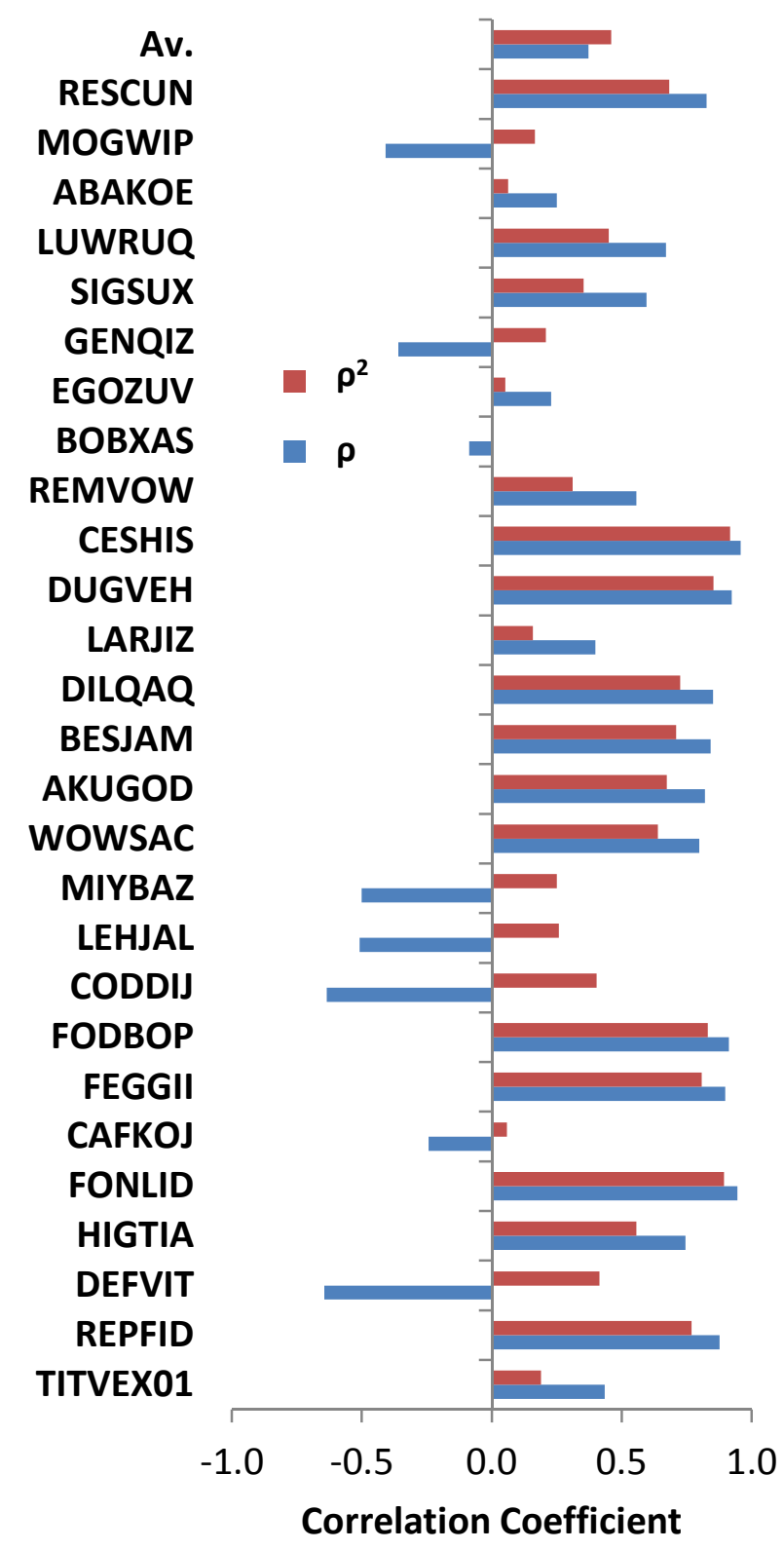

Figure 8. The $\rho^{2}$ and $\rho$ correlation coefficients obtained between PM7 relative conformational energies on PM7 geometries with coordination center fixed during optimization and M06/def2tzvp relative conformational energies on PBE-D3/def2-svp optimized geometries with PM7 optimized geometries used as starting point. 


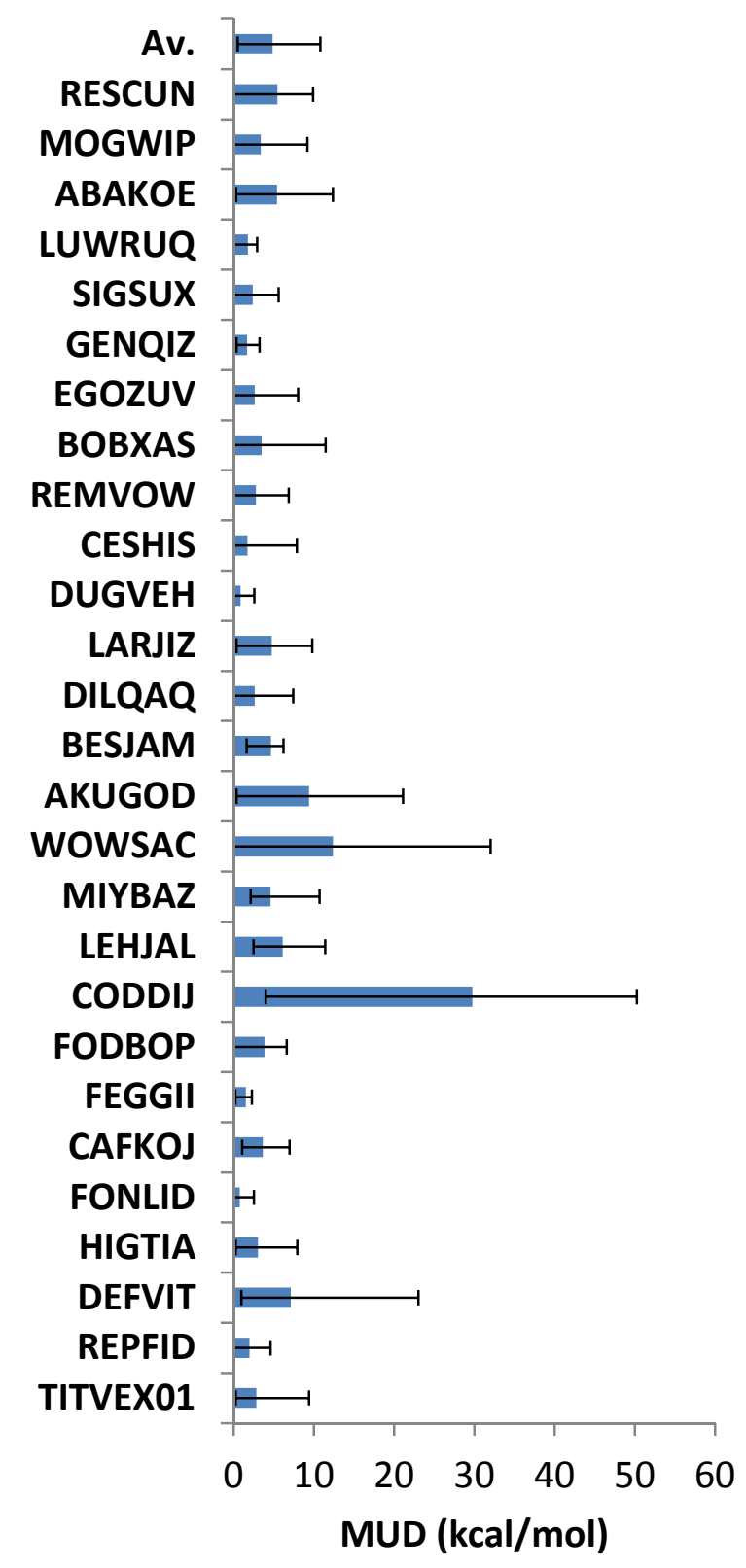

Figure 9. The mean unsigned deviation (MUD) values obtained between the PM7//PM7 (PM7 optimization with coordination center fixed) and M06/def2-tzvp//PBE-D3//def2-svp relative conformational energies for transition metal complexes studied in the present work. The solid bars indicate the average MUD value, and the ends of the solid lines at each bar give the lowest and the highest absolute deviation obtained for particular complexes. 
In Figure 9 the MUDs obtained between PM7//PME7 (optimization with fixed coordination center) and M06/def2-tzvp//PBE-D3/def2-svp conformational energies are presented for every complex together with the largest and lowest absolute deviations in the relative conformational energies. An average MUD turned out to be $4.9 \mathrm{kcal} / \mathrm{mol}$ which is $1.6 \mathrm{kcal} / \mathrm{mol}$ lower comparing to what was obtained for fully relaxed PM7 geometry optimizations in Section 3.2.1. The lowest MUD of $0.8 \mathrm{kcal} / \mathrm{mol}$ has been obtained for complex FONLID $\mathbf{H g}\left[\mathrm{CH}(\mathrm{COOEt})_{2}\right]_{2}$ and the largest MUD of $29.7 \mathrm{kcal} / \mathrm{mol}$ has been obtained for CODDIJ DET $<\left(\mathrm{PPh}_{2}\right)_{2}>\mathbf{P d C l}_{2}$.

Again the manual inspection of all the geometries has been performed. As all atoms forming the coordination center have been fixed during PM7 geometry optimization, distorted coordination center is not an origin of poorly predicted relative conformational energy. However, fixed coordination sphere does not eliminate another problem revealed for semiempirical methods in Section 3.2.1: incorrectly predicted coordination of some elements or functional groups to transition metal. Thus, during the PM7 geometry optimization of CODDIJ DET $<\left(\mathrm{PPh}_{2}\right)_{2}>\mathbf{P d C l}_{2}$ an unphysical coordination of one hydrogen atom in conformers 1, 2, 3, 5, 6, 8, 9 (see Figure S9 for conformer 1) or two hydrogen atoms in conformer 7 (see Figure S10) to Pd atom occurred. As no unphysical hydrogen coordination to Pd observed in conformers 0 and 4, these turned out to be significantly higher in energy according to PM7. DFT optimization removes false hydrogen coordination leading to significantly smaller energy diversity in conformational energies of CODDIJ DET $<\left(\mathrm{PPh}_{2}\right)_{2}>\mathbf{P d C l}_{2}$. Similar unphysical coordination of atoms/functional groups have also been found in $\mathrm{CAFKOJ}\left[(\mathrm{MeO})_{3} \mathrm{P}\right]_{3} \mathbf{I r}(\mathrm{CO})\left(\mathrm{O}\right.$ of $\mathrm{O}-\mathrm{CH}_{3}$ group coordinates to $\mathrm{Ir}$, see Figure S11), LEHJAL $\left[\mathrm{C}_{21} \mathrm{H}_{34} \mathrm{~N}_{3} \mathrm{O}\right]_{2} \mathbf{P d C l}{ }_{2}$ ( $\mathrm{H}$ of $\mathrm{CH}_{3}$ groups coordination to $\mathrm{Pd}$, see Figure $\mathrm{S} 12$ ), MIYBAZ [N,N-diBu-benzimidazoline $]_{2} \mathbf{P d I}_{2}\left(\mathrm{H}\right.$ of $\mathrm{CH}_{3}$ coordination to $\mathrm{Pd}$, see Figure $\left.\mathrm{S} 13\right)$, WOWSAC [MeOPh-Te-( $\left(\mathrm{CH}_{2}\right)_{2}-$ Morpholinyl $]_{2} \mathbf{P d C l}{ }_{2}\left(\mathrm{H}\right.$ of $\mathrm{CH}_{2}$ group coordination to $\mathrm{Pd}$, see 
Figure S14), REMVOW [propen-2-yl]-CH=C=Ru( $\left.\mathrm{PCy}_{3}\right)_{2} \mathrm{Cl}_{2}$ ( $\mathrm{H}$ of $\mathrm{CH}_{2}$ group coordination to $\mathrm{Ru}$, see Figure S15). Remarkably, large errors have also been obtained for complexes for which no unphysical coordination to metal atoms occurred, e.g. for $\mathrm{ABAKOE}(\mathrm{Ph}-\mathrm{N}-\mathrm{iPr})_{3} \mathbf{W}(=\mathrm{O}) \mathrm{Cl}$, DEFVIT $\left[(\mathrm{MeO})_{3} \mathrm{P}\right]_{3} \mathbf{C r}(\mathrm{CO})_{2}(\mathrm{CSe}), \quad \mathrm{RESCUN} \quad\left[\mathrm{C}_{11} \mathrm{H}_{9} \mathrm{~N}_{2}\right]-\left(\mathrm{CH}_{2}\right)_{4}-\mathrm{O}-\mathrm{Zr}(\mathrm{Furan}) \mathrm{Cl}_{4}$ indicating fundamental difference between the PES in DFT and semiempirical methods ${ }^{49}$ which sometimes results in a conformational change, see Figures S16-S18.

\section{Conclusion}

A set of contemporary PM6*/7 black-box semiempirical methods has been tested to reproduce the conformational energies of 27 realistic transition metal complexes of 16 transition metals related to homogeneous catalysis. An analysis of the conformational energies derived from the single point energy evaluations revealed a pronounced difference between semiempirical and DFT methods. While conformational energies obtained with DFT protocols perfectly group together, their $\mathrm{PM} 6^{*} / 7$ counterparts turned out to be significantly different for all but a few complexes. To identify an origin of the deviations, we re-optimized all the conformers with PM7 method followed by DFT optimization mimicking the conformational search procedure in organometallic chemistry. Comparison of thus obtained PM7-based and DFT-based relative conformational energies revealed large discrepancies for all but a few complexes, originated from fundamental differences in PESs often manifesting themselves in chemical transformations/distortion of coordination center geometry or false coordination of some atoms $(\mathrm{H}, \mathrm{O})$ to transition metals upon PM7 geometry optimization. To minimize these effects, we tried 
to perform PM7 geometry optimizations with fixed positions of all atoms composing the coordination sphere. Even if slight improvement in PM7 performance was achieved, still large discrepancies with DFT conformational energies have survived partly because fixing coordination center did not prevent false coordination of atoms to transition metal to saturate the coordination sphere. In cases where no false coordination was observed, an origin of the difference in conformational energies is the fundamental difference between PESs of DFT and semiempirical methods. Hence, in general the semiempirical methods are recommended for conformational search/sampling in transition metal complexes only after careful validation for particular complex. One possible origin of poor performance of the PM6*/PM7 semiempirical methods is related to a limited number of complexes in the MOPAC training set, ${ }^{141}$ often complexes containing necessary diatomic parameters are missing. For example, poor PM7 geometries obtained for TITVEX01 $\left(\mathrm{Ph}_{3} \mathrm{P}\right)_{3} \mathbf{A u G e C l}_{3}$ complex might be the result of absence of reliable $\mathrm{Au}$ - Ge diatomic parameters as there are no complexes both containing $\mathrm{Au}$ and $\mathrm{Ge}$ in the PM7 training set. ${ }^{141}$ Another origin is likely related to the fact that many experimental formation enthalpies tabulated in numerous databases as NIST webbook ${ }^{142-143}$ and utilized to train semiempirical have been found to be inaccurate. ${ }^{144-146} \mathrm{We}$ expect that careful reparameterization of semiempirical methods will significantly increase their accuracy for transition metal systems. The obtained database ${ }^{147}$ is promising with respect to testing of other strategies not covered by the present study as ligand field molecular mechanics (LFMM) method developed by Deeth et al. ${ }^{67}$ and available via upcoming Tinker release ${ }^{68}$ where additional energy terms describing the TM center are combined with standard force field terms responsible the organic part of the molecule, and alternative quantum mechanically derived force field $(\mathrm{QMDFF})^{148}$ or tight binding GFN-xTB ${ }^{36}$ approaches suggested by Grimme and co-workers. 


\section{ASSOCIATED CONTENT}

Supporting Information. Cartesian coordinates $(\AA)$ of PBE-D3/def2-svp and PM7 optimized structures, M06/def2-tzvp, PBE0-D3/def2-tzvp, PBE-D3/def2-svp, PM6, PM6-D3, PM6-DH+, PM6-DH2, PM6-DH2X, PM6-D3H4, PM6-D3H4X and PM7, tabulated values forming the basis of Figures $2-6$, Figures $8-9$ and Figures S1-S18, tabulated conformational energies. This material is available free of charge via the Internet at http://pubs.acs.org.

\section{AUTHOR INFORMATION}

\section{Corresponding Author}

*Yury.Minenkov@mipt.ru

*Luigi.Cavallo@kaust.edu.sa

\section{ACKNOWLEDGMENT}

We gratefully acknowledge Prof. Frank Jensen, Department of Chemistry, Aarhus University, Denmark, Prof. J. J. P. Stewart, Stewart Computational Chemistry, Colorado Springs, USA and Dr. Alexander M. Genaev, N. N. Vorozhtsov Institute of Organic Chemistry, Siberian Branch of the Russian Academy of Sciences, Novosibirsk, Russia for helpful discussions. The research reported in this publication was supported by funding from King Abdullah University of Science and Technology (KAUST). For computer time, this research used the resources of the Supercomputing Laboratory at King Abdullah University of Science and Technology (KAUST) in Thuwal, Saudi Arabia. Y.M. gratefully acknowledges support from the Government of the Russian Federation (Agreement № 074-02-2018-286). 


\section{REFERENCES}

1. Crabtree, R. H., The Organometallic Chemistry of the Transition Metals. Wiley: Hoboken, N. J., 2005.

2. $\quad$ Astruc, D., Organometallic Chemistry and Catalysis. Springer Berlin Heidelberg: 2007.

3. Grubbs, R. H., Homogeneous Catalysis : the Applications and Chemistry of Catalysis by Soluble Transition Metal Complexes. Ed. by Parshall, G.W and Ittel, S. D. Wiley: New York ; Chichester, 1980.

4. Davies, S. G.; Baldwin, J. E., Organotransition Metal Chemistry: Applications to Organic Synthesis: Applications to Organic Synthesis. Elsevier Science: Pergamon Press plc, Headington Hill Hall, Oxford OX3 oBW, England, 1982.

5. Ishii, Y.; Tsutsui, M., Organotransition-Metal Chemistry. Plenum Press: New York, 1975.

6. Comba, P.; Hambley, T. W.; Martin, B., Molecular Modeling of Inorganic Compounds. Wiley-VCH Verlag GmbH \& Co. KGaA: Weinheim, Germany, 2009.

7. Comba, P., Modeling of Molecular Properties. Wiley-VCH Verlag GmbH \& Co. KGaA: Weinheim, Germany, 2011.

8. Cramer, C. J.; Truhlar, D. G., Density Functional Theory for Transition Metals and Transition Metal Chemistry. Phys. Chem. Chem. Phys. 2009, 11, 10757-10816.

9. Lin, Z., Interplay between Theory and Experiment: Computational Organometallic and Transition Metal Chemistry. Acc. Chem. Res. 2010, 43, 602-611.

10. Frenking, G.; Wagener, T., Transition Metal Chemistry. In Encyclopedia of Computational Chemistry, John Wiley \& Sons, Ltd: 2002.

11. Bray, M. R.; Deeth, R. J.; Paget, V. J., Kinetics and Mechanism in Transition Metal Chemistry: A Computational Perspective. Prog. React. Kinet. 1996, 21, 169-214.

12. Cramer, C. J., Essentials of Computational Chemistry: Theories and Models. 2nd ed.; Wiley: Chichester, England, 2005.

13. Jensen, F., Introduction to Computational Chemistry. 2nd ed.; Wiley: Chichester, England, 2006; p 620.

14. Reiher, M., A Theoretical Challenge: Transition-Metal Compounds. Chimia 2009, 63, 140-145.

15. Harvey, J. N., On the Accuracy of Density Functional Theory in Transition Metal Chemistry. Annu. Rep. Prog. Chem., Sect. C: Phys. Chem. 2006, 102, 203-226.

16. Veillard, A., Quantum Chemistry: The Challenge of Transition Metals and Coordination Chemistry. Springer Netherlands: 2012.

17. Pierloot, K., Transition Metals Compounds: Outstanding Challenges for Multiconfigurational Methods. Int. J. Quantum Chem. 2011, 111, 3291-3301.

18. Bencini, A., Some Considerations on the Proper Use of Computational Tools in Transition Metal Chemistry. Inorg. Chim. Acta 2008, 361, 3820-3831.

19. Davidson, E. R., Computational Transition Metal Chemistry. Chem. Rev. 2000, 100, 351352.

20. Bersuker, I. B., Electronic Structure and Properties of Transition Metal Compounds: Introduction to the Theory. Wiley: Hoboken, N. J., 2010.

21. Van Eldik, R.; Harvey, J., Theoretical and Computational Inorganic Chemistry. Elsevier Science: Academic Press, London, England, 2010; Vol. 62. 
23. Lin, Z. Y., Interplay between Theory and Experiment: Computational Organometallic and Transition Metal Chemistry. Acc. Chem. Res. 2010, 43, 602-611.

24. Zhang, X. H.; Chung, L. W.; Wu, Y. D., New Mechanistic Insights on the Selectivity of Transition-Metal-Catalyzed Organic Reactions: The Role of Computational Chemistry. Acc. Chem. Res. 2016, 49, 1302-1310.

25. Zein, S.; Neese, F., Ab Initio and Coupled-Perturbed Density Functional Theory Estimation of Zero-Field Splittings in $\mathrm{Mn}^{\mathrm{II}}$ Transition Metal Complexes. J. Phys. Chem. A 2008, 112, 7976-7983.

26. Pantazis, D. A.; Orio, M.; Petrenko, T.; Zein, S.; Bill, E.; Lubitz, W.; Messinger, J.; Neese, F., A New Quantum Chemical Approach to the Magnetic Properties of Oligonuclear Transition-Metal Complexes: Application to a Model for the Tetranuclear Manganese Cluster of Photosystem II. Chem. - Eur. J. 2009, 15, 5108-5123.

27. Sarmiento-Perez, R.; Botti, S.; Marques, M. A. L., Optimized Exchange and Correlation Semilocal Functional for the Calculation of Energies of Formation. J. Chem. Theory Comput. 2015, 11, 3844-3850.

28. Huntington, L. M. J.; Nooijen, M., Application of Multireference Equation of Motion Coupled Cluster Theory to Transition Metal Complexes and an Orbital Selection Scheme for the Efficient Calculation of Excitation Energies. J. Chem. Phys. 2015, 142, 194111/1-194111/18. 29. Nooijen, M.; Lotrich, V., Extended Similarity Transformed Equation-of-Motion Coupled Cluster Theory (Extended-STEOM-CC): Applications to Doubly Excited States and Transition Metal Compounds. J. Chem. Phys. 2000, 113, 494-507.

30. Comba, P.; Hausberg, S.; Martin, B., Calculation of Exchange Coupling Constants of Transition Metal Complexes with DFT. J. Phys. Chem. A 2009, 113, 6751-6755.

31. Tchougreeff, A. L.; Soudackov, A. V., Effective Hamiltonian Crystal Fields: Present Status and Applicability to Magnetic Interactions in Polynuclear Transition Metal Complexes. Russ. J. Phys. Chem. A 2014, 88, 1904-1913.

32. Tchougreeff, A. L.; Soudackov, A. V.; van Leusen, J.; Koegerler, P.; Becker, K.-D.; Dronskowski, R., Effective Hamiltonian Crystal Field: Present Status and Applications to Iron Compounds. Int. J. Quantum Chem. 2016, 116, 282-294.

33. Sorkin, A.; Truhlar, D. G.; Amin, E. A., Energies, Geometries, and Charge Distributions of Zn Molecules, Clusters, and Biocenters from Coupled Cluster, Density Functional, and Neglect of Diatomic Differential Overlap Models. J. Chem. Theory Comput. 2009, 5, 1254-1265. 34. Bühl, M.; Kabrede, H., Geometries of Transition Metal Complexes from Density Functional Theory. J. Chem. Theory Comput. 2006, 2, 1282-1290.

35. Waller, M. P.; Bühl, M., Vibrational Corrections to Geometries of Transition Metal Complexes from Density Functional Theory. J. Comput. Chem. 2007, 28, 1531-1537.

36. Grimme, S.; Bannwarth, C.; Shushkov, P., A Robust and Accurate Tight-Binding Quantum Chemical Method for Structures, Vibrational Frequencies, and Noncovalent Interactions of Large Molecular Systems Parametrized for All spd-Block Elements $(Z=1-86) . J$. Chem. Theory Comput. 2017, 13, 1989-2009.

37. Goodpaster, J. D.; Barnes, T. A.; Manby, F. R.; Miller, T. F., III, Density Functional Theory Embedding for Correlated Wavefunctions: Improved Methods for Open-Shell Systems and Transition Metal Complexes. J. Chem. Phys. 2012, 137, 224113/1-224113/10. 
38. Atanasov, M.; Daul, C. A., Modeling Properties of Molecules with Open d-shells Using Density Functional Theory. C. R. Chim. 2005, 8, 1421-1433.

39. Darkhovskii, M. B.; Chugreev, A. L., Molecular Modeling of Transition-Metal Complexes with Open d-shell. Ross. Khim. Zh. 2004, 48, 93-102.

40. Tchougreeff, A. L.; Darkhovskii, M. B., Molecular Modelling of Metal Complexes with Open d-shell. Prog. Theor. Chem. Phys. 2006, 15, 451-505.

41. Hu, L.; Chen, K.; Chen, H., Modeling $\sigma$-Bond Activations by Nickel( 0$)$ Beyond Common Approximations: How Accurately Can We Describe Closed-Shell Oxidative Addition Reactions Mediated by Low-Valent Late 3d Transition Metal? J. Chem. Theory Comput. 2017, 13, 4841-4853.

42. Craciun, R.; Vincent, A. J.; Shaughnessy, K. H.; Dixon, D. A., Prediction of Reliable Metal- $\mathrm{PH}_{3}$ Bond Energies for $\mathrm{Ni}, \mathrm{Pd}$, and $\mathrm{Pt}$ in the 0 and +2 Oxidation States. Inorg. Chem. 2010, 49, 5546-5553.

43. Manivasagam, S.; Laury, M. L.; Wilson, A. K., Pseudopotential-Based Correlation Consistent Composite Approach (rp-ccCA) for First- and Second-Row Transition Metal Thermochemistry. J. Phys. Chem. A 2015, 119, 6867-6874.

44. Jiang, W.; DeYonker, N. J.; Determan, J. J.; Wilson, A. K., Toward Accurate Theoretical Thermochemistry of First Row Transition Metal Complexes. J. Phys. Chem. A 2012, 116, 870885 .

45. Mohr, M.; McNamara, J. P.; Wang, H.; Rajeev, S. A.; Ge, J.; Morgado, C. A.; Hillier, I. H., The Use of Methods Involving Semi-Empirical Molecular Orbital Theory to Study the Structure and Reactivity of Transition Metal Complexes. Faraday Discuss. 2003, 124, 413-428. 46. Waitt, C.; Ferrara, N. M.; Eshuis, H., Thermochemistry and Geometries for TransitionMetal Chemistry from the Random Phase Approximation. J. Chem. Theory Comput. 2016, 12, 5350-5360.

47. Li, P.; Merz, K. M., Jr., Metal Ion Modeling Using Classical Mechanics. Chem. Rev. 2017, 117, 1564-1686.

48. Fey, N.; Harvey, J. N.; Lloyd-Jones, G. C.; Murray, P.; Orpen, A. G.; Osborne, R.; Purdie, M., Computational descriptors for chelating P,P- and P,N-donor ligands. Organometallics 2008, 27, 1372-1383.

49. Gillespie, A. M.; Morello, G. R.; White, D. P., De novo ligand design: Understanding stereoselective olefin binding to $\left[\left(\eta^{5}-\mathrm{C}_{5} \mathrm{H}_{5}\right) \mathrm{Re}(\mathrm{NO})\left(\mathrm{PPh}_{3}\right)\right]^{+}$with molecular mechanics, semiempirical quantum mechanics, and density functional theory. Organometallics 2002, 21, 3913-3921.

50. Balcells, D.; Drudis-Sole, G.; Besora, M.; Dolker, N.; Ujaque, G.; Maseras, F.; Lledos, A., Some critical issues in the application of quantum mechanics/molecular mechanics methods to the study of transition metal complexes. Faraday Discuss. 2003, 124, 429-441.

51. Buda, C.; Burt, S. K.; Cundari, T. R.; Shenkin, P. S., De novo structural prediction of transition metal complexes: Application to technetium. Inorg. Chem. 2002, 41, 2060-2069.

52. Cundari, T. R., The Application of Modern Computational Chemistry Methods to Organometallic Systems. 2007; Vol. 1, p 639-669.

53. Suarez, D.; Diaz, N.; Lopez, R., A Combined Semiempirical and DFT Computational Protocol for Studying Bioorganometallic Complexes: Application to Molybdocene-Cysteine Complexes. J. Comput. Chem. 2014, 35, 324-334. 
54. Suarez, D.; Diaz, N., Molecular Modeling of Bioorganometallic Compounds:

Thermodynamic Properties of Molybdocene-Glutathione Complexes and Mechanism of Peptide Hydrolysis. Chemphyschem 2015, 16, 1646-1656.

55. Besora, M.; Braga, A. A. C.; Ujaque, G.; Maseras, F.; Lledos, A., The importance of conformational search: a test case on the catalytic cycle of the Suzuki-Miyaura cross-coupling. Theor. Chem. Acc. 2011, 128, 639-646.

56. Deeth, R. J., General molecular mechanics method for transition metal carboxylates and its application to the multiple coordination modes in mono- and dinuclear $\mathrm{Mn}$ (II) complexes. Inorg. Chem. 2008, 47, 6711-6725.

57. Drudis-Sole, G.; Ujaque, G.; Maseras, F.; Lledos, A., A QM/MM study of the asymmetric dihydroxylation of terminal aliphatic n-alkenes with $\mathrm{OsO}_{4} \cdot(\mathrm{DHQD})_{2} \mathrm{PYDZ}$ : Enantioselectivity as a function of chain length. Chem. Eur. J. 2005, 11, 1017-1029. 58. Bartol, J.; Comba, P.; Melter, M.; Zimmer, M., Conformational searching of transition metal compounds. J. Comput. Chem. 1999, 20, 1549-1558.

59. Grimme, S.; Bannwarth, C.; Dohm, S.; Hansen, A.; Pisarek, J.; Pracht, P.; Seibert, J.; Neese, F., Fully Automated Quantum-Chemistry-Based Computation of Spin-Spin-Coupled Nuclear Magnetic Resonance Spectra. Angew. Chem. Int. Ed. 2017, 56, 14763-14769. 60. Vilkov, L. V.; Pentin, Y. A., Physical Research Methods in Chemistry. Structural Methods and Optical Spectroscopy. Mir: Moscow, 2003; 683.

61. Hechinger, M.; Leonhard, K.; Marquardt, W., What is Wrong with Quantitative Structure-Property Relations Models Based on Three-Dimensional Descriptors? J. Chem. Inf. Model. 2012, 52, 1984-1993.

62. Rappe, A. K.; Casewit, C. J.; Colwell, K. S.; Goddard, W. A.; Skiff, W. M., UFF, a Full Periodic Table Force Field for Molecular Mechanics and Molecular Dynamics Simulations. $J$. Am. Chem. Soc. 1992, 114, 10024-10035.

63. Rappe, A. K.; Colwell, K. S.; Casewit, C. J., Application of a Universal Force Feild to Metal Complexes. Inorg. Chem. 1993, 32, 3438-3450.

64. Comba, P.; Remenyi, R., Inorganic and bioinorganic molecular mechanics modeling - the problem of the force field parameterization. Coord. Chem. Rev. 2003, 238, 9-20.

65. Norrby, P. O.; Brandt, P., Deriving force field parameters for coordination complexes. Coord. Chem. Rev. 2001, 212, 79-109.

66. Hansen, E.; Rosales, A. R.; Tutkowski, B.; Norrby, P. O.; Wiest, O., Prediction of Stereochemistry using Q2MM. Acc. Chem. Res. 2016, 49, 996-1005.

67. Deeth, R. J.; Anastasi, A.; Diedrich, C.; Randell, K., Molecular Modelling for Transition Metal Complexes: Dealing with d-electron Effects. Coord. Chem. Rev. 2009, 253, 795-816.

68. Foscato, M.; Deeth, R. J.; Jensen, V. R., Integration of Ligand Field Molecular Mechanics in Tinker. J. Chem. Inf. Model. 2015, 55, 1282-1290.

69. Sabolovic, J.; Gomzi, V., Structure Prediction of Bis(amino acidato)copper(II)

Complexes with a New Force Field for Molecular Modeling. J. Chem. Theory Comput. 2009, 5, 1940-1954.

70. Tubert-Brohman, I.; Schmid, M.; Meuwly, M., Molecular Mechanics Force Field for Octahedral Organometallic Compounds with Inclusion of the Trans Influence. J. Chem. Theory Comput. 2009, 5, 530-539.

71. Minenkov, Y.; Occhipinti, G.; Jensen, V. R., Metal-Phosphine Bond Strengths of the Transition Metals: A Challenge for DFT. J. Phys. Chem. A 2009, 113, 11833-11844. 
72. Minenkov, Y.; Occhipinti, G.; Heyndrickx, W.; Jensen, V. R., The Nature of the Barrier to Phosphane Dissociation from Grubbs Olefin Metathesis Catalysts. Eur. J. Inorg. Chem. 2012, 1507-1516.

73. Feldgus, S.; Landis, C. R., Origin of enantioreversal in the rhodium-catalyzed asymmetric hydrogenation of prochiral enamides and the effect of the alpha-substituent. Organometallics 2001, 20, 2374-2386.

74. Feldgus, S.; Landis, C. R., Large-scale computational modeling of Rh(DuPHOS) (+)catalyzed hydrogenation of prochiral enamides: Reaction pathways and the origin of enantioselection. J. Am. Chem. Soc. 2000, 122, 12714-12727.

75. Landis, C. R.; Feldgus, S., A simple model for the origin of enantioselection and the anti "lock-and-key" motif in asymmetric hydrogenation of enamides as catalyzed by chiral diphosphine complexes of Rh(I). Angew. Chem. Int. Ed. 2000, 39, 2863-2866.

76. Ujaque, G.; Maseras, F.; Lledos, A., Theoretical characterization of an intermediate for the $[3+2]$ Cycloaddition Mechanism in the Bis(dihydroxy- quinidine)-3,6-Pyridazine-Osmium Tetroxide-Catalyzed dihydroxylation of styrene. J. Org. Chem. 1997, 62, 7892-7894.

77. Ujaque, G.; Maseras, F.; Lledos, A., Theoretical study on the origin of enantioselectivity in the Bis(dihydroquinidine)-3,6-pyridazine-Osmium Tetroxide-catalyzed dihydroxylation of styrene. J. Am. Chem. Soc. 1999, 121, 1317-1323.

78. Stewart, J. J. P., Semiempirical Molecular Orbital Methods. In Rev. Comput. Chem., John Wiley \& Sons, Inc.: 2007; pp 45-81.

79. Thiel, W., Semiempirical Quantum-Chemical Methods. WIREs Comput. Mol. Sci. 2014, $4,145-157$.

80. Dewar, M. J. S.; Thiel, W., Ground States of Molecules. 38. MNDO Method Approximations and Parameters. J. Am. Chem. Soc. 1977, 99, 4899-4907.

81. Dewar, M. J. S.; Zoebisch, E. G.; Healy, E. F.; Stewart, J. J. P., The Development and Use of Quantum Mechanical Molecular Models. 76. AM1 - A New General Purpose Quantum Mechanical Molecular Model. J. Am. Chem. Soc. 1985, 107, 3902-3909.

82. Yilmazer, N. D.; Korth, M., Prospects of Applying Enhanced Semi-Empirical QM Methods for Virtual Drug Design. Current Medicinal Chemistry 2016, 23, 2101-2111.

83. Yilmazer, N. D.; Korth, M., Enhanced semiempirical QM methods for biomolecular interactions. Computational and Structural Biotechnology Journal 2015, 13, 169-175.

84. Rocha, G. B.; Freire, R. O.; Simas, A. M.; Stewart, J. J. P., RM1: A reparameterization of AM1 for H, C, N, O, P, S, F, Cl, Br, and I. J. Comput. Chem. 2006, 27, 1101-1111.

85. Stewart, J. J. P., Optimization of Parameters for Semiempirical Methods. 1. Method. J. Comput. Chem. 1989, 10, 209-220.

86. Stewart, J. J. P., Optimization of Parameters for Semiempirical Methods. 2. Applications. J. Comput. Chem. 1989, 10, 221-264.

87. Stewart, J. J. P., Optimization of Parameters for Semiempirical Methods. 3. Extension of $\mathrm{PM} 3$ to $\mathrm{Be}, \mathrm{Mg}, \mathrm{Zn}, \mathrm{Ga}, \mathrm{Ge}, \mathrm{As}, \mathrm{Se}, \mathrm{Cd}$, In, Sn, Sb, Te, Hg, Tl, Pb, and Bi. J. Comput. Chem. 1991, 12, 320-341.

88. Hoffmann, R., An Extended Hückel Theory. I. Hydrocarbons. J. Chem. Phys. 1963, 39, 1397.

89. Pariser, R.; Parr, R. G., A Semi-Empirical Theory of the Electronic Spectra and Electronic Structure of Complex Unsaturated Molecules. 1. J. Chem. Phys. 1953, 21, 466-471. 90. Pariser, R.; Parr, R. G., A Semi-Empirical Theory of the Electronic Spectra and Electronic Structure of Complex Unsaturated Molecules. 2. J. Chem. Phys. 1953, 21, 767-776. 
91. Pople, J. A., Electron Interaction in Unsaturated Hydrocarbons. J. Chem. Soc. Faraday Trans. 1953, 49, 1375-1385.

92. Stewart, J. J. P., Special Issue - MOPAC - a Semiempirical Molecular Orbital Program. $J$. Comput. Aided Mol. Des. 1990, 4, 1-45.

93. Kayi, H.; Clark, T., AM1* Parameters for Copper and Zinc. J. Mol. Model. 2007, 13, 965-979.

94. Kayi, H.; Clark, T., AM1* Parameters for Vanadium and Chromium. J. Mol. Model. 2009, 15, 1253-1269.

95. Kayi, H.; Clark, T., AM1* Parameters for Bromine and Iodine. J. Mol. Model. 2009, 15, 295-308.

96. Kayi, H.; Clark, T., AM1* Parameters for Manganese and Iron. J. Mol. Model. 2010, 16, 1109-1126.

97. Kayi, H.; Clark, T., AM1* Parameters for Cobalt and Nickel. J. Mol. Model. 2010, 16, 29-47.

98. Kayi, H.; Clark, T., AM1* Parameters for Palladium and Silver. J. Mol. Model. 2011, 17, 2585-2600.

99. Filatov, M. Y.; Zil'berberg, I. L.; Zhidomirov, G. M., NDDO for Metal Compounds (NDDO/MC): A New Semiempirical SCF-MO Method for Transition Metal Complexes. Int. J. Quantum Chem. 1992, 44, 565-85.

100. Zilberberg, I. L.; Zhidomirov, G. M., Semiempirical NDDO/MC Calculations of the Excited States of the Chromate Ion. J. Struct. Chem. 1999, 40, 187-191.

101. Chugreev, A. L., New Generation of Semiempirical Methods of Molecular Modeling Based on the Theory of Group Functions. J. Struct. Chem. 2007, 48, S32-S54.

102. Ramírez-Solís, A., On the Performance of Local, Semilocal, and Nonlocal ExchangeCorrelation Functionals on Transition Metal Molecules. J. Chem. Phys. 2007, 126, 224105/1224105/12.

103. Bredow, T.; Geudtner, G.; Jug, K., MSINDO Parameterization for Third-Row Transition Metals. J. Comput. Chem. 2001, 22, 861-887.

104. Imhof, P.; Noe, F.; Fischer, S.; Smith, J. C., AM1/d Parameters for Magnesium in Metalloenzymes. J. Chem. Theory Comput. 2006, 2, 1050-1056.

105. Winget, P.; Clark, T., AM1* Parameters for Aluminum, Silicon, Titanium and Zirconium. J. Mol. Model. 2005, 11, 439-456.

106. Børve, K. J.; Jensen, V. R.; Karlsen, T.; Stovneng, J. A.; Swang, O., Evaluation of PM3(TM) as a Geometry Generator in Theoretical Studies of Transition Metal-Based Catalysts for Polymerizing Olefins. J. Mol. Model. 1997, 3, 193-202.

107. Cundari, T. R.; Deng, J., PM3(TM) Analysis of Transition-Metal Complexes. J. Chem. Inf. Comput. Sci. 1999, 39, 376-381.

108. Gorelsky, S. I. In Semiempirical SCF MO Methods, Electronic Spectra, and configurational interaction, Elsevier Ltd.: 2004; pp 467-489.

109. Praveen, P. A.; Babu, R. R.; Ramamurthi, K., Theoretical and Experimental Investigations on Linear and Nonlinear Optical Response of Metal Complexes Doped PMMA Films. Materials Research Express 2017, 4, 025024.

110. Stewart, J. J. P., An Investigation into the Applicability of the Semiempirical Method PM7 for Modeling the Catalytic Mechanism in the Enzyme Chymotrypsin. J. Mol. Model. 2017, $23,154$. 
111. Christensen, A. S.; Kubar, T.; Cui, Q.; Elstner, M., Semiempirical Quantum Mechanical Methods for Noncovalent Interactions for Chemical and Biochemical Applications. Chem. Rev. 2016, 116, 5301-5337.

112. Stewart, J. J. P., Optimization of Parameters for Semiempirical Methods V: Modification of NDDO Approximations and Application to 70 Elements. J. Mol. Model. 2007, 13, 1173-1213. 113. Stewart, J. J. P., Optimization of Parameters for Semiempirical Methods VI: More Modifications to the NDDO Approximations and Re-optimization of Parameters. J. Mol. Model. 2013, 19, 1-32.

114. Borve, K. J.; Jensen, V. R.; Karlsen, T.; Stovneng, J. A.; Swang, O., Evaluation of PM3(tm) as a geometry generator in theoretical studies of transition-metal-based catalysts for polymerizing olefins. J. Mol. Model. 1997, 3, 193-202.

115. Decker, S. A.; Donini, O.; Klobukowski, M., A contribution to the understanding of carbonyl migration in $\mathrm{Mn}-2(\mathrm{CO})(10)$ via the pairwise exchange mechanism. J. Phys. Chem. A 1997, 101, 8734-8740.

116. Occhipinti, G.; Bjørsvik, H. R.; Jensen, V. R., Quantitative structure-activity relationships of ruthenium catalysts for olefin metathesis. J. Am. Chem. Soc. 2006, 128, 69526964.

117. Groom, C. R.; Bruno, I. J.; Lightfoot, M. P.; Ward, S. C., The Cambridge Structural Database. Acta Crystallogr. B 2016, 72, 171-179.

118. Grimme, S.; Antony, J.; Ehrlich, S.; Krieg, H., A Consistent and Accurate Ab Initio Parametrization of Density Functional Dispersion Correction (DFT-D) for the 94 Elements H-Pu. J. Chem. Phys. 2010, 132, 154104.

119. Korth, M., Third-Generation Hydrogen-Bonding Corrections for Semiempirical QM Methods and Force Fields. J. Chem. Theory Comput. 2010, 6, 3808-3816.

120. Rezac, J.; Fanfrlik, J.; Salahub, D.; Hobza, P., Semiempirical Quantum Chemical PM6 Method Augmented by Dispersion and H-Bonding Correction Terms Reliably Describes Various Types of Noncovalent Complexes. J. Chem. Theory Comput. 2009, 5, 1749-1760.

121. Korth, M.; Pitoňák, M.; Řezáč, J.; Hobza, P., A Transferable H-Bonding Correction for Semiempirical Quantum-Chemical Methods. J. Chem. Theory Comput. 2010, 6, 344-352.

122. Rezáč, J.; Hobza, P., A Halogen-Bonding Correction for the Semiempirical PM6 Method. Chem. Phys. Lett. 2011, 506, 286-289.

123. Ǩezáč, J.; Hobza, P., Advanced Corrections of Hydrogen Bonding and Dispersion for Semiempirical Quantum Mechanical Methods. J. Chem. Theory Comput. 2012, 8, 141-151. 124. Brahmkshatriya, P. S.; Dobeš, P.; Fanfrlík, J.; Řezáč, J.; Paruch, K.; Bronowska, A.; Lepšík, M.; Hobza, P., Quantum Mechanical Scoring: Structural and Energetic Insights into Cyclin-Dependent Kinase 2 Inhibition by Pyrazolo[1,5-a]pyrimidines. Current Computer-Aided Drug Design 2013, 9, 118-129.

125. Perdew, J. P.; Burke, K.; Ernzerhof, M., Generalized Gradient Approximation Made Simple. Phys. Rev. Lett. 1996, 77, 3865-3868.

126. Perdew, J. P.; Burke, K.; Ernzerhof, M., Generalized Gradient Approximation Made Simple. Phys. Rev. Lett. 1997, 78, 1396-1396.

127. Frisch, M. J.; Trucks, G. W.; Schlegel, H. B.; Scuseria, G. E.; Robb, M. A.; Cheeseman, J. R.; Scalmani, G.; Barone, V.; Mennucci, B.; Petersson, G. A.; Nakatsuji, H.; Caricato, M.; Li, X.; Hratchian, H. P.; Izmaylov, A. F.; Bloino, J.; Zheng, G.; Sonnenberg, J. L.; Hada, M.; Ehara, M.; Toyota, K.; Fukuda, R.; Hasegawa, J.; Ishida, M.; Nakajima, T.; Honda, Y.; Kitao, O.; Nakai, H.; Vreven, T.; Montgomery Jr., J. A.; Peralta, J. E.; Ogliaro, F.; Bearpark, M. J.; Heyd, 
J.; Brothers, E. N.; Kudin, K. N.; Staroverov, V. N.; Kobayashi, R.; Normand, J.; Raghavachari, K.; Rendell, A. P.; Burant, J. C.; Iyengar, S. S.; Tomasi, J.; Cossi, M.; Rega, N.; Millam, N. J.; Klene, M.; Knox, J. E.; Cross, J. B.; Bakken, V.; Adamo, C.; Jaramillo, J.; Gomperts, R.; Stratmann, R. E.; Yazyev, O.; Austin, A. J.; Cammi, R.; Pomelli, C.; Ochterski, J. W.; Martin, R. L.; Morokuma, K.; Zakrzewski, V. G.; Voth, G. A.; Salvador, P.; Dannenberg, J. J.; Dapprich, S.; Daniels, A. D.; Farkas, Ö.; Foresman, J. B.; Ortiz, J. V.; Cioslowski, J.; Fox, D. J. Gaussian 09, Gaussian, Inc.: Wallingford, CT, USA, 2009.

128. Minenkov, Y.; Cavallo, L., Ground-State Gas-Phase Structures of Inorganic Molecules Predicted by Density Functional Theory Methods. ACS Omega 2017, 2, 8373-8387.

129. Girichev, G. V.; Giricheva, N. I.; Koifman, O. I.; Minenkov, Y. V.; Pogonin, A. E.; Semeikin, A. S.; Shlykov, S. A., Molecular Structure and Bonding in Octamethylporphyrin Tin(II), $\mathrm{SnN}_{4} \mathrm{C}_{28} \mathrm{H}_{28}$. Dalton Trans. 2012, 41, 7550-7558.

130. Waller, M. P.; Braun, H.; Hojdis, N.; Bühl, M., Geometries of Second-Row Transition Metal Complexes from Density Functional Theory. J. Chem. Theory Comput. 2007, 3, 22342242.

131. Bühl, M.; Reimann, C.; Pantazis, D. A.; Bredow, T.; Neese, F., Geometries of Third-Row Transition-Metal Complexes from Density Functional Theory. J. Chem. Theory Comput. 2008, 4, 1449-1459.

132. Rydberg, P.; Olsen, L., The Accuracy of Geometries for Iron Porphyrin Complexes from Density Functional Theory. J. Phys. Chem. A 2009, 113, 11949-11953.

133. Minenkov, Y.; Singstad, Å.; Occhipinti, G.; Jensen, V. R., The Accuracy of DFTOptimized Geometries of Functional Transition Metal Compounds: A Validation Study of Catalysts for Olefin Metathesis and Other Reactions in the Homogeneous Phase. Dalton Trans. 2012, 41, 5526-5541.

134. Hujo, W.; Grimme, S., Performance of Non-Local and Atom-Pairwise Dispersion Corrections to DFT for Structural Parameters of Molecules with Noncovalent Interactions. $J$. Chem. Theory Comput. 2013, 9, 308-315.

135. Pandey, K. K.; Patidar, P.; Bariya, P. K.; Patidar, S. K.; Vishwakarma, R., Assessment of Density Functionals and Paucity of Non-Covalent Interactions in Aminoylyne Complexes of Molybdenum and Tungsten $\left[\left(\eta^{5}-\mathrm{C}_{5} \mathrm{H}_{5}\right)(\mathrm{CO})_{2} \mathrm{M} \equiv \mathrm{EN}\left(\mathrm{SiMe}_{3}\right)(\mathrm{R})\right](\mathrm{E}=\mathrm{Si}, \mathrm{Ge}, \mathrm{Sn}, \mathrm{Pb}): \mathrm{A}$ Dispersion-Corrected DFT Study. Dalton Trans. 2014, 43, 9955-9967.

136. Weigend, F.; Ahlrichs, R., Balanced Basis Sets of Split Valence, Triple Zeta Valence and Quadruple Zeta Valence Quality for H to Rn: Design and Assessment of Accuracy. Phys. Chem. Chem. Phys. 2005, 7, 3297-3305.

137. Andrae, D.; Häussermann, U.; Dolg, M.; Stoll, H.; Preuss, H., Energy-Adjusted Abinitio Pseudopotentials for the Second and Third Row Transition Elements. Theor. Chim. Acta 1990, 77, 123-141.

138. Johnson, E. R.; Becke, A. D.; Sherrill, C. D.; DiLabio, G. A., Oscillations in MetaGeneralized-Gradient Approximation Potential Energy Surfaces for Dispersion-Bound Complexes. J. Chem. Phys. 2009, 131, 034111.

139. Johnson, E. R.; Mackie, I. D.; DiLabio, G. A., Dispersion Interactions in Density Functional Theory. J. Phys. Org. Chem. 2009, 22, 1127-1135.

140. Stewart, J. J. P. MOPAC2016, Stewart Computational Chemistry, Colorado Springs, CO, USA, http://openmopac.net, 2016.

141. Stewart, J. J. P. http://openmopac.net/PM7 accuracy/molecules.html. (accessed $02 / 12 / 2016)$. 
142. Chase, M. W., Jr, NIST-JANAF Themochemical Tables, Fourth Edition. J. Phys. Chem. Ref. Data 1998, Monograph 9, 1-1951.

143. NIST Chemistry Webbook, NIST Standard Reference Database Number 69, Eds. P.J. Linstrom and W.G. Mallard, National Institute of Standards and Technology, Gaithersburg MD, 20899, http://webbook.nist.gov, (retrieved December 27, 2017). .

144. Minenkov, Y.; Sliznev, V. V.; Cavallo, L., Accurate Gas Phase Formation Enthalpies of Alloys and Refractories Decomposition Products. Inorg. Chem. 2017, 56, 1386 - 1401.

145. Thanthiriwatte, K. S.; Vasiliu, M.; Battey, S. R.; Lu, Q.; Peterson, K. A.; Andrews, L.; Dixon, D. A., Gas Phase Properties of $\mathrm{MX}_{2}$ and $\mathrm{MX}_{4}(\mathrm{X}=\mathrm{F}, \mathrm{Cl})$ for $\mathrm{M}=$ Group 4, Group 14, Cerium, and Thorium. J. Phys. Chem. A 2015, 119, 5790-5803.

146. Vasiliu, M.; Feller, D.; Gole, J. L.; Dixon, D. A., Structures and Heats of Formation of Simple Alkaline Earth Metal Compounds: Fluorides, Chlorides, Oxides, and Hydroxides for Be, Mg, and Ca. J. Phys. Chem. A 2010, 114, 9349-9358.

147. Minenkov, Y.; Sharapa, D.; Cavallo, L., Accurate conformational energies of large realistic-size trasition metal complexes with bulky ligands. https://doi.org/10.6084/m9.figshare.c.4041149. 2018.

148. Grimme, S., A General Quantum Mechanically Derived Force Field (QMDFF) for Molecules and Condensed Phase Simulations. J. Chem. Theory Comput. 2014, 10, 4497-4514.

For Table of Contents use only

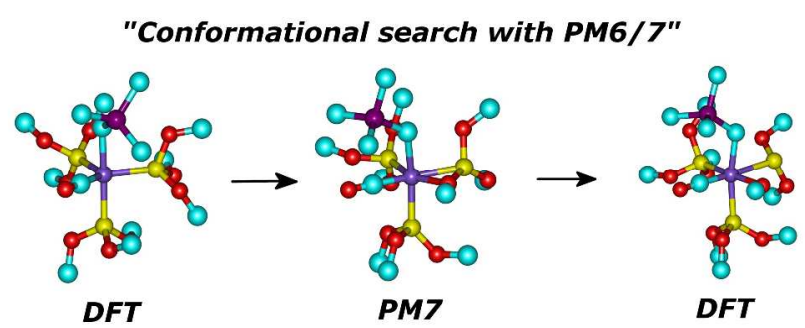

